\title{
Engineering Analysis of Measured Rotational Ground Motions at GVDA
}

\author{
Jianming Yin ${ }^{\mathrm{a}}$, Robert L. Nigbor ${ }^{\mathrm{b}, *}$, Qingjun Chen $^{\mathrm{a}}$, and Jamison Steidl ${ }^{\mathrm{c}}$ \\ ${ }^{a}$ State Key Laboratory of Disaster Reduction in Civil Engineering, Tongji University, Shanghai, China \\ ${ }^{\mathrm{b}}$ Department of Civil and Environment Engineering, University of California, Los Angeles, CA, USA \\ ${ }^{c}$ Earth Research Institute, University of California, Santa Barbara, CA, USA
}

\begin{abstract}
Characteristics of rotational earthquake ground motions and their effects on structural response are not yet well-defined. Recording rotational ground motions directly in free field is in its infancy, and simultaneous sixcomponent earthquake measurements are being accumulated slowly. A six-degree-of-freedom (6DOF) ground motion observation system was installed in the Garner Valley Downhole Array (GVDA), a very well-characterized and wellinstrumented geotechnical array in Southern California. Since 2008, six-component free-field earthquake ground motions have been recorded from hundreds of earthquakes with a relatively wide range of hypocentral distances and magnitudes. In this paper, analysis was conducted to develop the characteristics of these measured rotational ground motions. Linear relationships between peak rotation velocity and peak ground acceleration were found, similar to previous 6DOF measurements in Taiwan and Japan. Ratios of rotation to translation as a function of hypocentral distance show larger ground rotations at closer distance, and that rotational ground motions tend to attenuate more rapidly than corresponding translational ground motions. Measured rotational motions show differences from estimations using elastic plane wave theory when using simple local apparent wave velocities. Finally, preliminary empirical relationships for rotational response spectra are estimated for earthquake engineering applications.
\end{abstract}

Keywords: Garner Valley Downhole Array; rotational ground motions; rocking; torsion; peak ground acceleration; elastic wave theory; spectra ratio, strong ground motion, earthquake

\section{Introduction}

Earthquake motions of a rigid body can be described fully by six components: three translations (along the $\mathrm{x}, \mathrm{y}$ and $\mathrm{z}$ axes) and three rotations(about the $\mathrm{x}, \mathrm{y}$, and $\mathrm{z}$ axes). Translational earthquake ground motion forms the basis for traditional seismology and earthquake engineering research and practice. Rotational earthquake ground motions and their effects on structural response are a subject of active research but the lack of good records of rotational strong ground motion prevents this research from progressing [1]. Rotational ground motions are still largely ignored in seismic design of structures, dynamic response estimates of structures subjected to earthquake-induced base excitations are simplified by ignoring the rotational components of ground motion.

There is considerable evidence that rotational components are responsible for structural damage during earthquakes. Hart et al. [2] ascribed large torsional response of high-rise buildings during the 1971 the San Fernando, California, earthquake to torsional ground motions. De la Llera and Chopra [3], and also Ghayamaghamian et al. [4], studied the effectiveness of accidental eccentricity considering torsional ground motions. Both suggested that the 5\% accidental eccentricity in building design code is efficient for structures with periods longer than 0.3 sec. However, for stiff structures with shorter period, the structural response could increase when torsional excitations are included. Trifunac [5] qualitatively pointed out that strong motion rotations play a significant role in the response of structures near earthquake faults. As reported by Kozak [6], and more recently by Cucci et al. [7, 8] and Sargeant et al. [9], a number of rotational effects on vertically configured objects such as chimneys, pillars, capitals and gravestones were observed during historical and recent earthquakes, mostly observed in the near field. Absent direct measurements, it is not possible to determine whether the observed earthquake rotational effects are due to true rotational shaking or caused by translational ground motion input to asymmetric structures. However, rotational effect observations on freefield-based objects may be considered a potential indicator of pure rotational ground motion. For the increasing 
requirements of structural safety and sophisticated structural response analysis, there is a need for direct observation of six-component ground motions and for better understanding of the rotational ground motion components.

Efforts to observe rotational motions and their effects on structural response continue. By assuming that ground motions occur in a linear-elastic, homogenous half-space and that ground rocking is generated by $\mathrm{P}$, SV and Rayleigh waves, and ground torsion generated by SH waves and Love waves, some researchers have tried to calculate the point rotations based on elastic plane wave theory [10-12]. These classical assumptions may not hold for very strong ground motions and may underestimate ground rotations by several times in near-field $[13,14]$. Other researchers deduced rotational motions of ground or man-made structure indirectly from multiple translational seismometers, which gives the spatially averaged rotations, not the point rotations. This might only be appropriate when the wavelengths are much longer than the separation distance of the translational recordings. This limitation directly results in relatively narrow frequency-band rotations [15-22].

Direct measurement of six-degree-of-freedom (6DOF) ground motions with modern instrumentation started in 1994, when Nigbor [23] succeeded in observing significant amounts of near-field rotational motions from a very large explosion using a solid-state rotational sensor. Soon afterwards, with similar instruments, Takeo [13] recorded nearsource rotational earthquake ground motions during an earthquake swarm at offshore region of Ito in Izu peninsula, Japan. Then in 2004, Liu et al. [14]deployed a high-resolution triaxial rotational velocity sensor (the R-1 from eentec/PMD) at HGSD station in eastern Taiwan. During their phase 2 operation (from 8 May 2007 to 17 February 2008), many good rotational ground records (with signal-to-noise ratio $>5$ ) were obtained from 52 local earthquakes. Their preliminary analysis showed an approximately linear relationship between peak ground rotational velocity(PRV) and peak ground translational acceleration(PGA) [24].

The Garner Valley Downhole Array (GVDA) in Southern California has been an active geotechnical research site since the 1980's [25], focusing on the measurement of surface and subsurface ground motions to assess soil site response. It has been an experimental component of the National Science Foundation's Network for Earthquake Engineering Simulation (NEES) since 2004. GVDA is very close to major faults with high seismic activity. This has allowed the robust measurement of thousands of earthquakes from near- to far-field [26]. Rotational ground motion monitoring has been part of the GVDA instrumentation portfolio since 2004. A new high resolution rotational ground motion sensor was installed in 2008. In this paper, we will introduce the 6DOF ground motion observations at GVDA, describe a unique data set of earthquake recordings, perform statistical analyses on the characteristics of rotational components, compare measured rotations to those estimated by traditional linear elastic theory, and discuss engineering application of these empirical rotational ground motions.

\section{Simultaneous 6DOF ground motion measurements at GVDA}

The Garner Valley Downhole Array is located in a narrow valley within the Peninsular Range batholith in one of the most seismically active regions in Southern California. It is $7 \mathrm{~km}$ from the San Jacinto fault, $35 \mathrm{~km}$ from the San Andreas fault, and even closer to some minor faults. GVDA is a geotechnical earthquake engineering research site with a primary purpose of studying site response, soil-foundation-structure interaction and liquefaction. As such it has been thoroughly characterized by geotechnical and geophysical tests and is very well instrumented for surface and subsurface ground motions. The near-surface soil beneath the site has $17 \mathrm{~m}$ of silty sand, clayey sand, and silty gravel over granite bedrock with an approximately $33 \mathrm{~m}$ weathering profile until competent bedrock is attained. Average shear wave velocity in the upper $30 \mathrm{~m}\left(v_{30}\right)$ is $280 \mathrm{~m} / \mathrm{s}$. Details of the site characterization are found in Youd et al. [25]. This exceptionally well-characterized and well-instrumented site provides an ideal test bed for the empirical study of all six components of earthquake ground motions.

The surface layout of the instrumentation at GVDA is shown in Fig. 1. Location code 21 represents the rotational triaxial velocity sensor and location code 00,07 10, 12 represent translational triaxial accelerometers on the ground surface. The rotational ground motion sensor is an Eentec Model R-1. This sensor used magneto-hydro dynamic technology to sense the three components of rotational velocity with a frequency range of $0.03-50 \mathrm{~Hz}$. Details on the sensor performance are found in Nigbor et al. [27]. A closer look at the 6DOF ground motion instruments with one R-1 sensor and two accelerometers is shown in Fig. 2. 
Accelerometers for sensing translational ground motion are traditional force-balance servo accelerometers. At GVDA, these are Kinemetrics Model ES-T, with frequency response from $0-200 \mathrm{~Hz}$ and sub-micro-g resolution. Data acquisition is by 24-bit digital dataloggers recording GPS-synchronized samples at a 200 sample per second rate. Data from the more than 100 channels at GVDA are recorded continuously both locally and remotely at the University of California at Santa Barbara through a complex data communications system. More details about the instrumentation of the GVDA observation system and also the site characterization is available on the official website (http://www.nees.ucsb.edu/facilities/gvda, last accessed on January 2015).

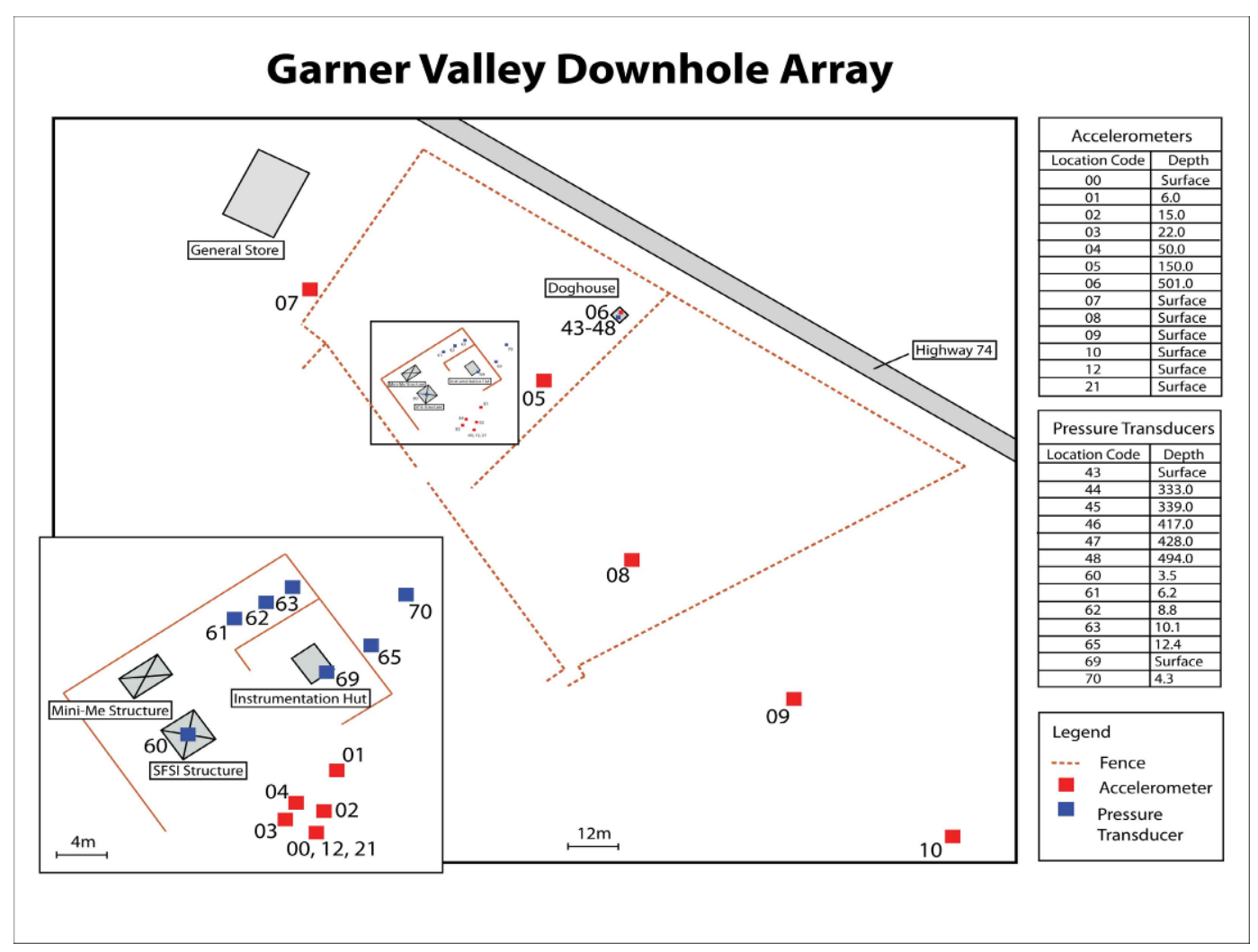

Fig. 1. Surface layout of instrumentation system at GVDA(http://www.nees.ucsb.edu/facilities/gvda, last accessed on January 2015); 


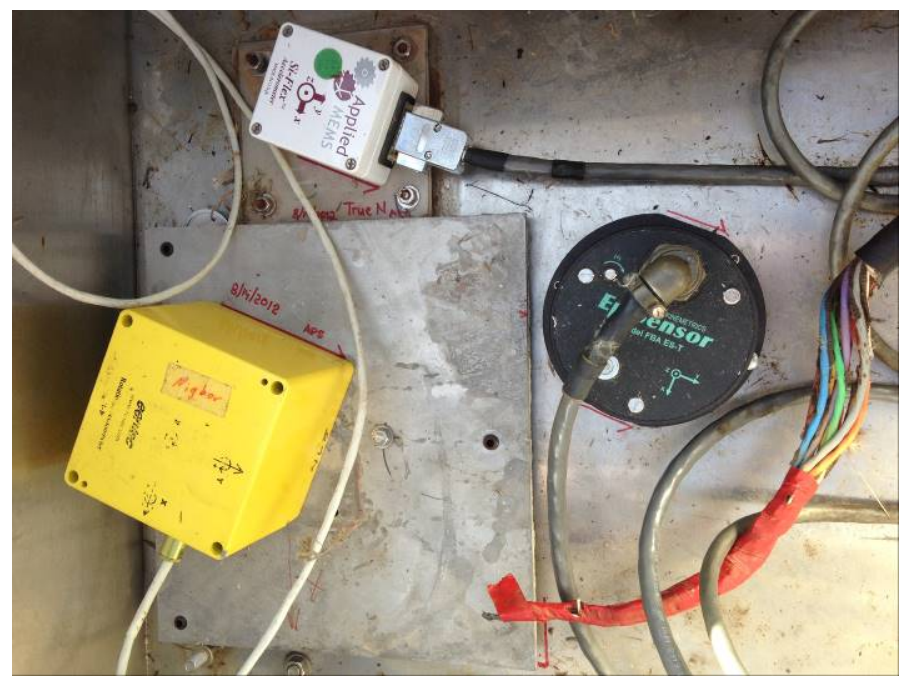

Fig. 2. 6DOF observation instruments deployed in GVDA site. The yellow box is the Eentec model R-1 rotational sensor (location code 21), the black cylinder is the Kinemetrics ES-T translational accelerometer (location code 00).

From 11 October 2008 to 30 December 2014, 215 events were recorded with a wide range of earthquake magnitudes from 3.0 to 7.2 , and a wide range of hypocentral distances from $14 \mathrm{~km}$ to $207 \mathrm{~km}$. Among these 215 events, 74 events have a PGA larger than $0.004 \mathrm{~m} / \mathrm{s} / \mathrm{s}$, with good signal-noise ratios and relatively wide useable frequency bandwidths. Distribution of these 74 earthquake epicenters is shown in Fig. 3. Information about these recorded earthquakes is listed in Table1. During this period, the magnitude 7.2 EI Mayor-Cucapah Earthquake of April 4th 2010 was also recorded with translational and rotational components. Data are shown in Fig. 4. It is generally noted in the figures of this paper that NS, EW and UD represent respectively the translational components along north-south, eastwest, and vertical axis. ROTNS and ROTEW represent rotational component about north-south and east-west axis, respectively, both called rocking components. ROTUD represents the rotational component about vertical axis, which is called torsion. For this major earthquake the hypocentral distance from GVDA is $207 \mathrm{~km}$, the PGA is $0.32 \mathrm{~m} / \mathrm{s} / \mathrm{s}$ along east-west direction, and the corresponding PRV is the rocking component around north-south axis, $0.18 \mathrm{mrad} / \mathrm{s}$. Several near-field events with hypocentral distance less than $20 \mathrm{~km}$ were measured. The closest earthquake is the event 14995172 with a hypocentral distance of $14.5 \mathrm{~km}$. 6DOF ground motion waveforms for this event are shown in Fig. 5. 


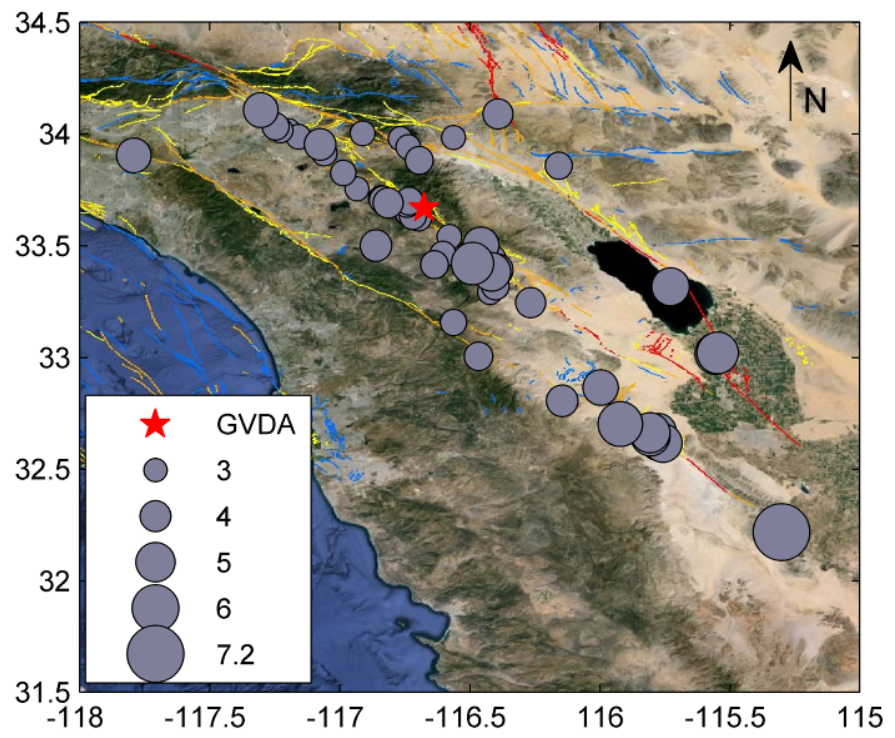

Fig. 3. Distribution of earthquake epicenters with 6DOF ground motions recorded in GVDA from 11 October 2008 to 30 December 2014, selected for PGA $>=0.004 \mathrm{~m} / \mathrm{s} / \mathrm{s}$. The pentagram stands for the GVDA observation site, and earthquake dot size is proportional to the earthquake magnitude as shown in the legend. Also shown are quaternary faults of Southern California [28], which show that most observed earthquakes occurred along the San Jacinto and San Andreas fault zones.
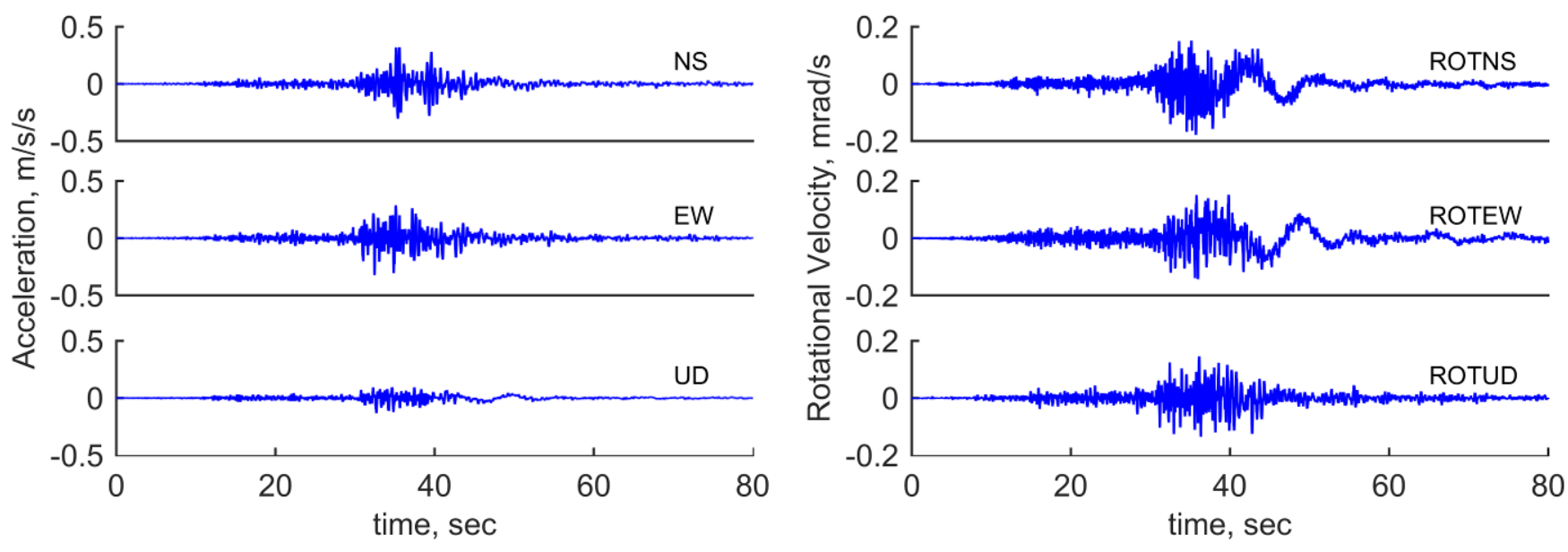

Fig. 4. Measured 6DOF ground motions of event14607652, the magnitude $M_{W} 7.2$ EI Mayor-Cucapah earthquake happened on April $4^{\text {th }} 2010$ 22:40:42(UTC) with a hypocentral distance $207 \mathrm{~km}$. 

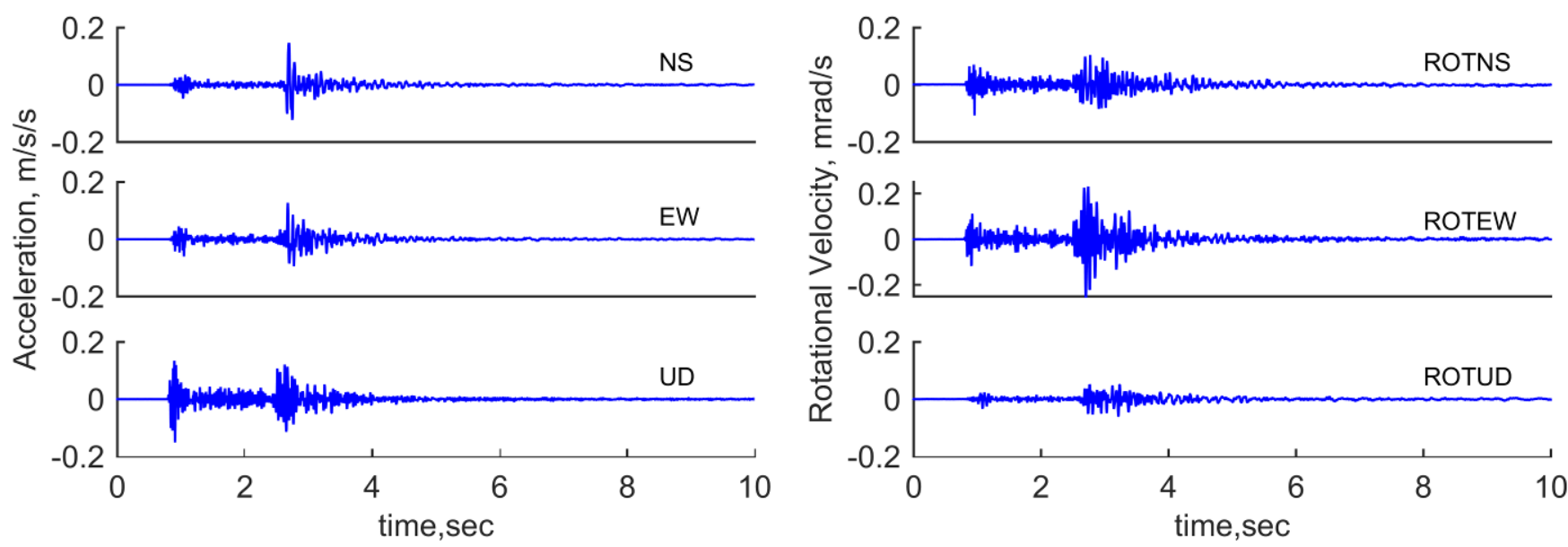

Fig. 5. Measured 6DOF ground motions of event 14995172, with a closest hypocentral distance 14.5km, Magnitude $M_{L}=3.1$, occurred on $3^{\text {rd }}$ June 2011 at 05:45:24(UTC).

\section{Data processing}

It is important to note that the R-1 sensor has a specified bandwidth $0.03-50 \mathrm{~Hz}$ (http://www.eentec.com/R1_data_new.htm, last accessed September 2014) but does not have a flat response in this bandwidth. This was confirmed by the laboratory and field testing of Nigbor et al. [27]. The raw measured rotational data are corrected for instrument response in the band $0.03-50 \mathrm{~Hz}$ by deconvolving the R-1's nominal transfer function (Eq.1). Translational accelerations also go through similar instrument correction using the manufacturer-provided pole-zero frequency response. No correction is needed for the data acquisition system, since the R-1 sensor and the triaxial accelerometers share the same GPS-synchronized 24-bit data logger with sample rate of 200sps and matched digital anti-aliasing filtering using linear-phase filters with constant group delay.

The nominal frequency response of the Model R-1 rotational sensor is given by:

$$
W(\omega)=\frac{A_{0} \omega^{2}}{\left[\left(s-p_{1}\right)\left(s-p_{2}\right)\left(s-p_{3}\right)\left(s-p_{4}\right)\left(s-p_{5}\right)\right]}
$$

Where

$$
\begin{aligned}
& A_{0}=1.669 \times 10^{9}\left[(\mathrm{rad} / \mathrm{sec})^{3} \times v /(\mathrm{rad} / \mathrm{sec})\right], \\
& \omega=\text { circular frequency }, \\
& s=i \omega=\text { complex frequency } \\
& p_{1}=0.13 \mathrm{rad} / \mathrm{sec}(0.02 \mathrm{~Hz}), \\
& p_{2}=0.25 \mathrm{rad} / \mathrm{sec}(0.04 \mathrm{~Hz}), \\
& p_{3}=144 \mathrm{rad} / \mathrm{sec}(23 \mathrm{~Hz}), \\
& p_{4}=408 \mathrm{rad} / \mathrm{sec}(65 \mathrm{~Hz}), \text { and } \\
& p_{5}=565 \mathrm{rad} / \mathrm{sec}(90 \mathrm{~Hz}),
\end{aligned}
$$

After sensor response deconvolution, noise reduction by bandpass filtering is the second necessary step for a useful seismogram. This is especially true for small earthquake events where the signal dips below the combined ambient ground vibrations and instrument noise at low and high frequencies. We follow the iterative filtering process used in 
the standardized processing of translational strong motion records for the PEER NGA database [29]. The signal-noise spectra and visual inspection of integrated displacement time series are used as a guide to select low-and high-cut frequencies, and a zero phase band pass acausal butterworth 6-pole filter is employed at both ends of the spectrum to remove signal energy that is dominated by noise. For a single event, all six components share the same filter parameters to retain the phase characteristics of the motions and avoid offsets in time scale of one component with respect to another [30]. The selected bandwidth will be different for different events. For our 6DOF data set, the filter cut-off is generally controlled by rotational components since they usually have a lower signal-noise ratio than the translational components, particularly in the lower frequency range. The signal and pre-event noise Fourier amplitude spectra for Event 14995172 are shown in Fig. 6. It can be seen that the translational components have a better signal noise ratio and wider reliable bandwidth, while the rotational data dip below sensor noise at both low and high frequency ends of the signal energy.
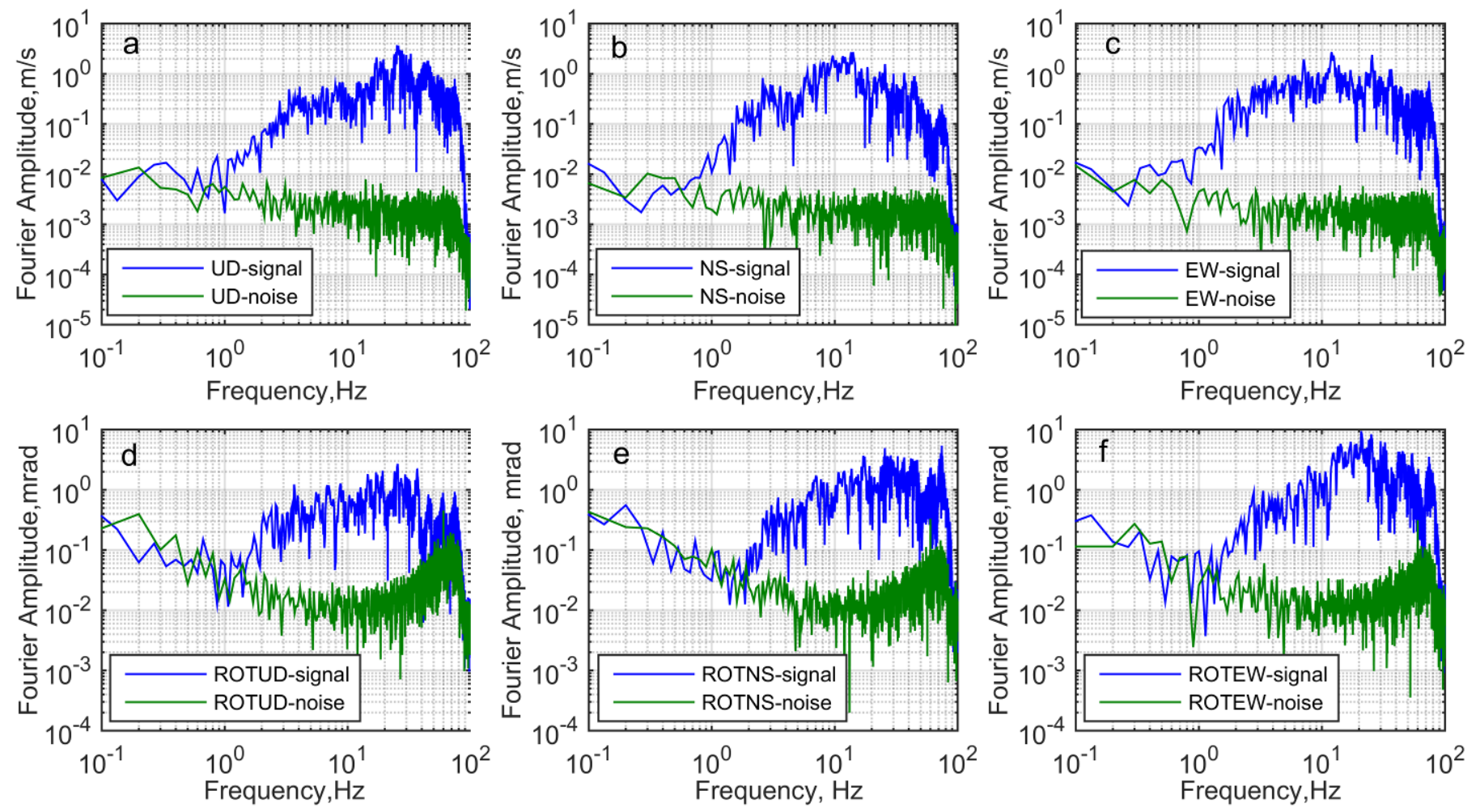

Fig. 6. Signal-noise Fourier Amplitude Spectra for event14995172,(a) (b) (c) for three translational components , and

(d) (e) (f) for three rotational components.

For this near-field event, a uniform $2-40 \mathrm{~Hz}$ bandwidth is chosen for filtering all six components. Then the rotational velocities are differentiated to rotational acceleration in the frequency domain using forward and inverse FFT calculations. The translational velocity, displacement and also rotational angle are calculated by integrating translational acceleration and rotational velocity. Fig. 7(a)-(c) show all six components for this event in a convenient format for illustrative purpose. For the rotational components, the rocking components are comparable and have relatively higher frequency content and higher peak values than torsional component. All waveforms have gone through similar data processing, and then were analyzed statistically to identify the engineering parameters of 6DOF ground motions in following sections. 

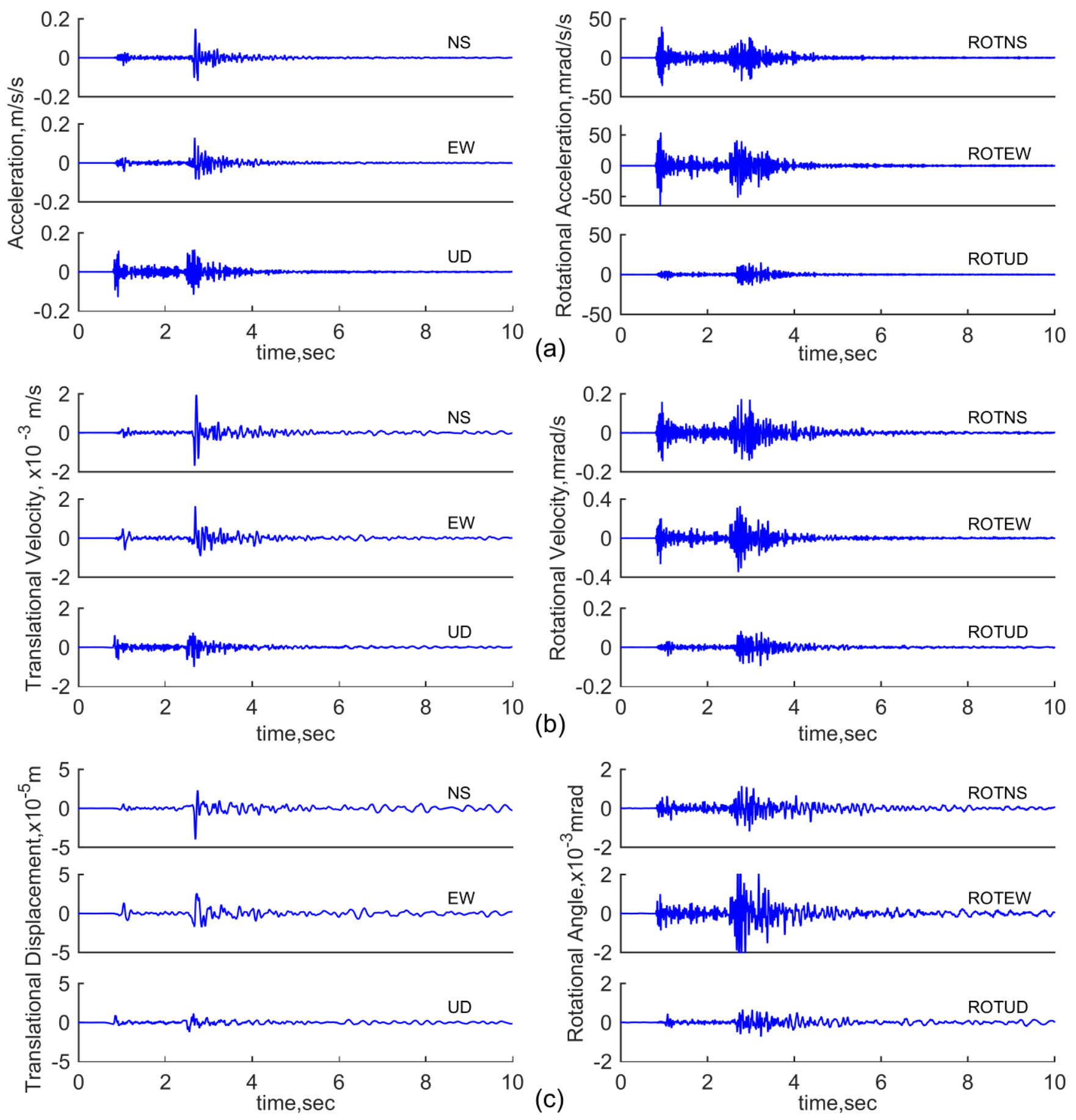

Fig. 7. Processed 6DOF data of event 14995172, (a). accelerations; (b).velocities; (c).translational displacements and rotational angles.

\section{Analysis of recorded 6DOF data}

\subsection{Characteristics of rotational ground motions at GVDA}

To date available rotational earthquake ground motion data are very limited. 6DOF ground motions have been recorded at a few unique stations like GVDA. Available rotational data are still insufficient to estimate attenuation 
relationships or produce empirical ground motion prediction equations as is now robustly done with translational ground motion data. However, by comparing simultaneous 6DOF components of ground motion we can begin to find some similarities and differences between the characteristics of the rotational and translational components. In the absence of broader monitoring of rotational ground motions, this will be start to understanding the characteristics of rotational ground motions.

Previous 6DOF ground motion observations in Taiwan and Japan by Lee et al. [24] and Takeo [31], respectively, have suggested an approximate linear relationship between PRV and PGA. This new GVDA data set shares this linear relationship as shown in Fig. 8. Among the three rotational components at GVDA, the rocking components are larger than the torsional component for most events. Therefore, the PRV values at GVDA actually comes from the rocking components. However, rotational data from the HGSD station in Taiwan showed that torsional components are mostly larger than rocking components. After this observation we conducted a field check to ensure the correct instrumentation orientation and found no mistake in our rotational or translational sensor channels. The explanation for such difference may be attributed to the different site conditions and different source types in Taiwan and California.

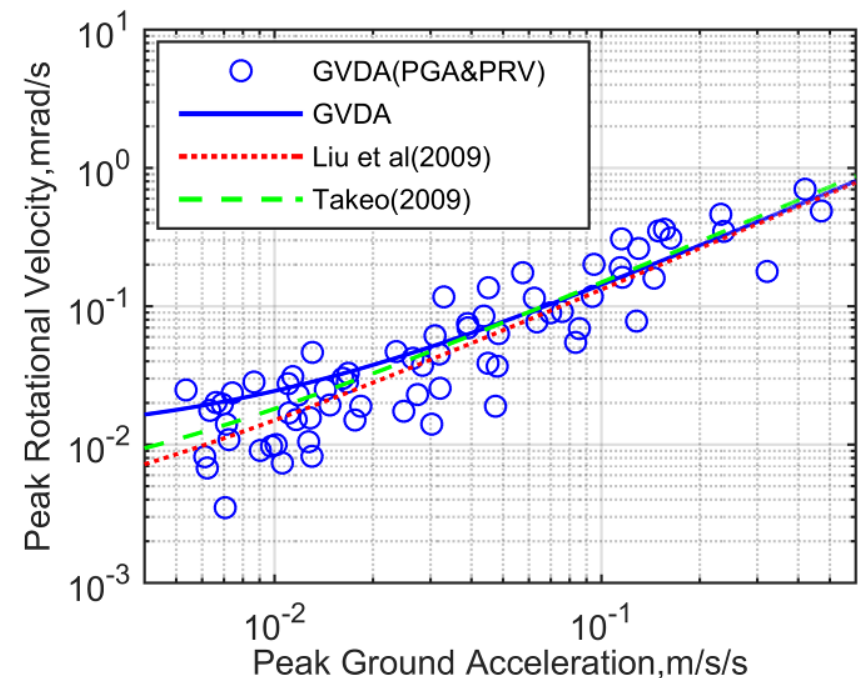

Fig. 8. PRV versus PGA (both after processing) of ground motions recorded in GVDA, also shown here are linear relationships suggested by Lee et al. [24] and Takeo [31].

\subsubsection{Dominant frequencies}

The ratio of peak velocity and peak acceleration (Vmax/Amax) has been used as an approximate measure of the dominant frequency content of a ground motion. A higher value of the ratio usually means a relatively lower dominant frequency [32]. For traditional translational ground motions, the dependence of this ratio on site effects, earthquake magnitude and hypocentral distance has been studied by McGuire, showing that the ratio increases with increasing earthquake magnitude and increasing source-to-site distance [33]. Here we give the ratios for all six components (Fig. 9) from our data set. It can be seen that the rotational components contain higher dominant frequencies than translational components for all earthquake magnitudes and hypocentral distances. 

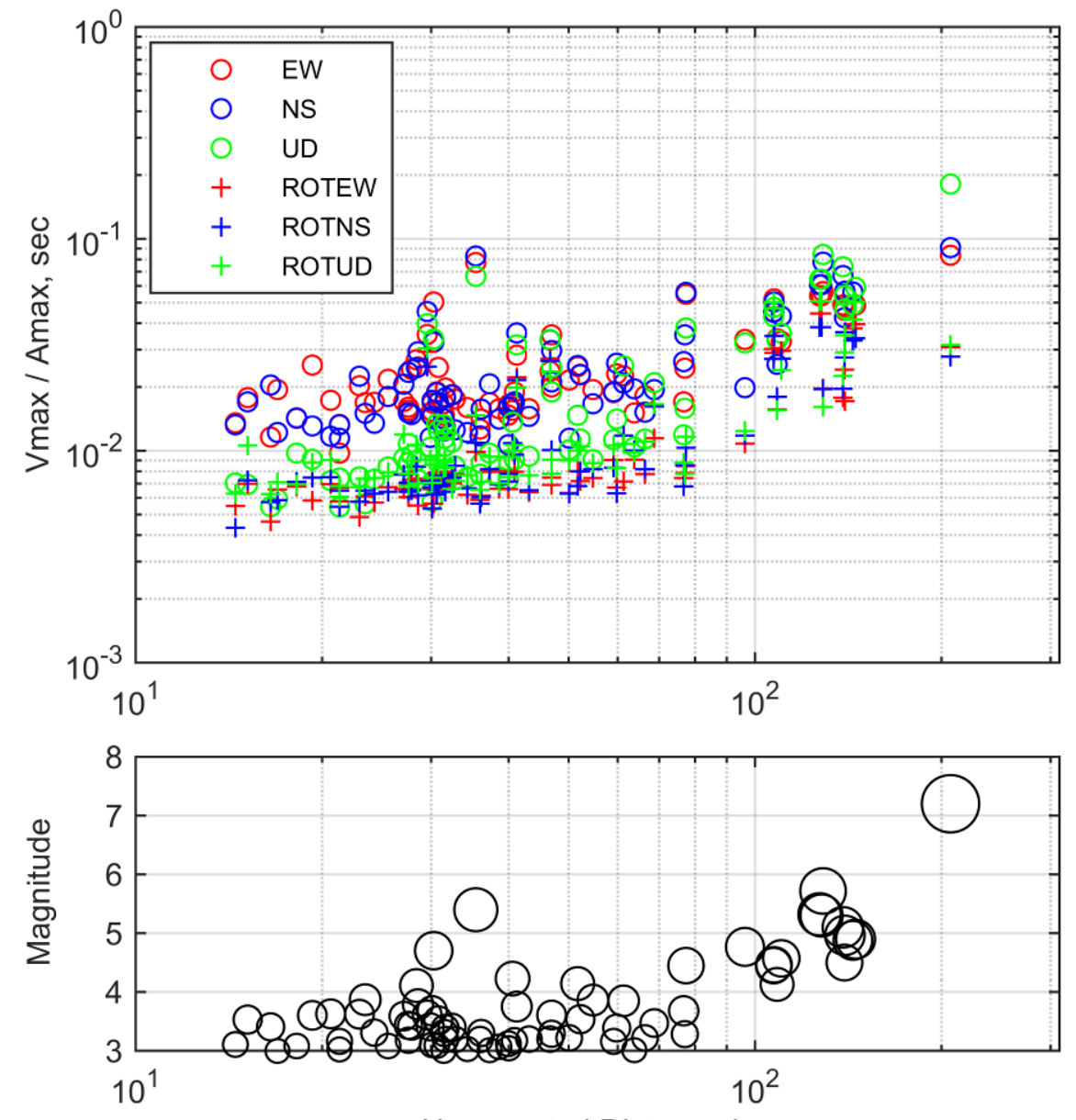

Hypocentral Distance,km

Fig. 9. above. Ratio of peak velocities (Vmax) and peak acceleration (Amax) for each channel of six components versus hypocentral distance for recordings in GVDA, approximate dominant circular frequency ( $2 \pi \mathrm{f}$ ) is the inverse of this ratio; below. Local magnitude of observed seismic events along hypocentral distance, sample circle size is proportional to the magnitude.

\subsubsection{Attenuation}

Attenuation relationships for earthquake ground motions are important for both seismology and engineering, allowing empirical estimation of ground motions. Much research has been conducted about the attenuation of translational ground accelerations based on a worldwide ground motion data set [29].

It is not yet possible to attempt similar work for rotational ground motions because of the limited rotational ground motion data and observation locations. As before, we argue that a useful working assumption for this limited data is that rotational motion attenuation will be similar to translational component attenuation.

Earthquake ground motions can be generally represented by :

$$
Y=f(M) * f(R) * f(S)
$$

where $\mathrm{Y}$ is the seismic intensity parameter of interest (peak ground acceleration, response spectrum and so on), $\mathrm{M}$ is the magnitude, and $\mathrm{R}$ is the hypocentral distance, $f(M)$ is the source function to represent the earthquake energy 
release, $f(R)$ represents the wave propagation effect and geometry attenuation of the ground motions, and $f(S)$ is the site response where the motions are recorded.

The rotational ground motions and translational ground motions from an earthquake source share common features such as source mechanism, wave propagation path, and site condition. By comparing rotational ground motions and translational ground motions, we may derive some characteristics about the rotational ground motions attenuation with hypocentral distance. Ratios of the peak ground rotational acceleration (PRA) to PGA are shown in Fig. 10; also shown are the ratios for peak velocity and displacement.

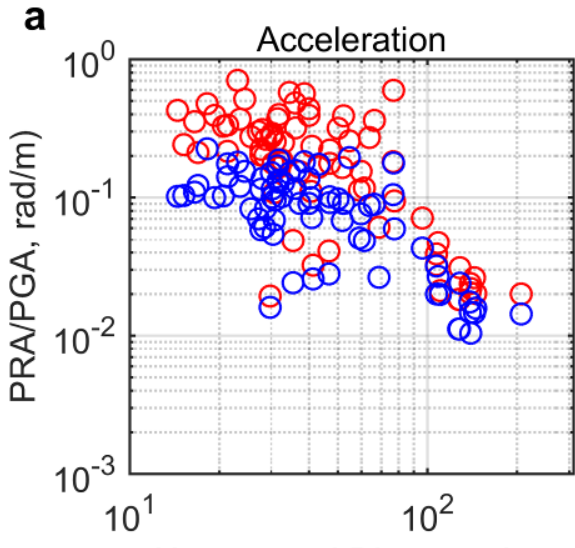

Hypocentral Distance, km

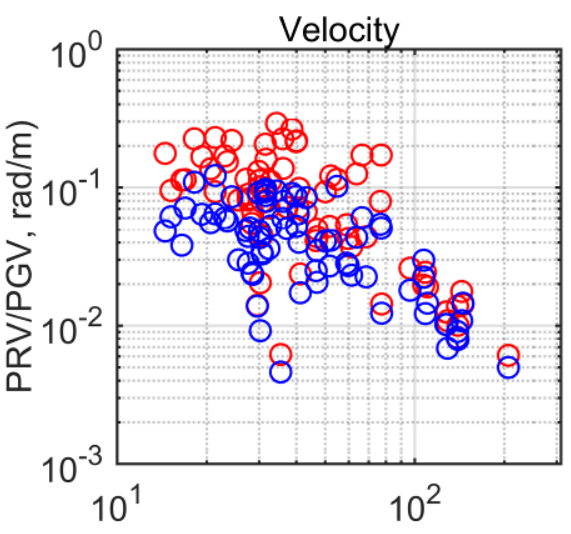

Hypocentral Distance, km

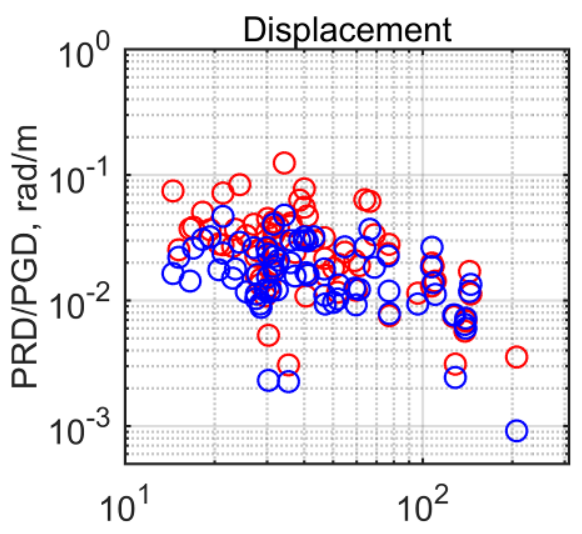

Hypocentral Distance, km

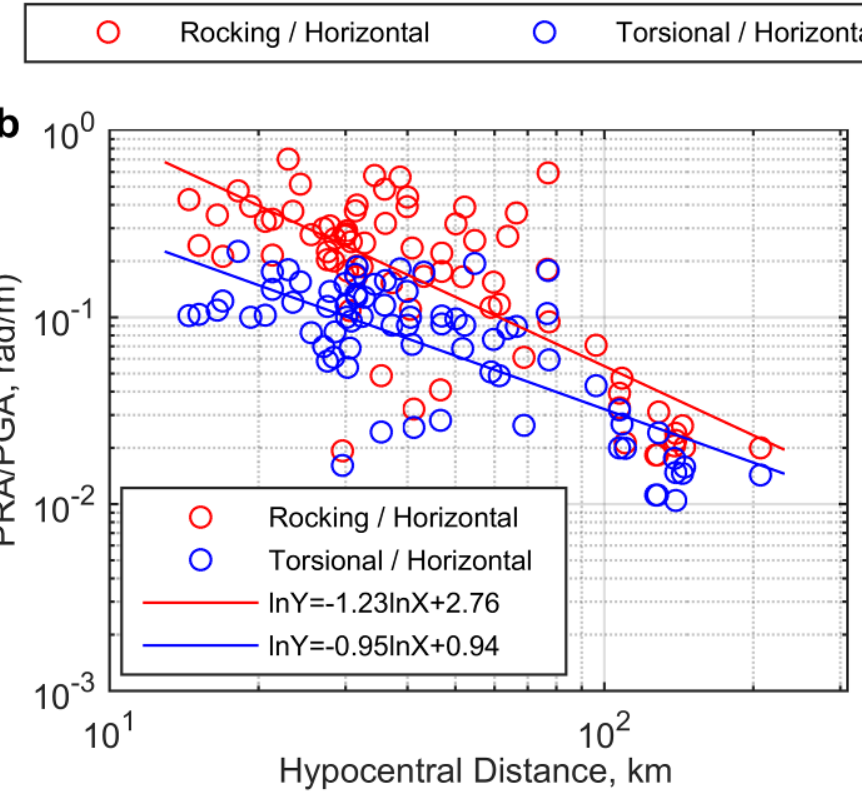

Fig. 10. (a). Ratios of the peak rotational ground motions to peak horizontal ground motions (acceleration, velocity and displacement). (b). Ratios of the peak rotational acceleration to peak horizontal acceleration as a function of hypocentral distance and fitted curves for observed earthquake events recorded at GVDA.

The qualitative trend of the ratios shows larger ground rotations at closer distance. It also shows that rotational ground motions attenuate much more rapidly than translational ground motions with distance. Among the rotational components, the rocking component is generally larger than torsional component and attenuates more rapidly than the torsional component. Two exponential curves were least-square fitted to represent the trend of the ratios. When combined with traditional attenuation patterns of horizontal ground motion, they can be used to preliminarily estimate rotational ground motions where translational ground motions are available. However, this observation is limited to this specific single station because of the data set used in the analysis. Building complete empirical attenuation 
relationships for rotational components will need more observations, especially spatially distributed recordings for a same earthquake.

\subsection{Comparison of measured rotational motions with elastic wave theory}

Based on classical elastic plane wave theory $[10,11]$, seismic plane waves propagate along a path line linking the source point to the site. Seismic ground motion is calculated as by plane harmonic body waves. The torsional rotational component (ground rotations around vertical direction) and rocking rotational components (ground rotations around transverse direction) are related to vertical and transverse translational acceleration, respectively, through the following relationship:

$$
\begin{aligned}
& \dot{\theta}_{V}(t)=-\frac{\ddot{u}_{T}(t)}{2 C_{a p p}} \\
& \dot{\theta}_{T}(t)=\frac{\ddot{u}_{V}(t)}{C_{a p p}}
\end{aligned}
$$

where the subscript $V$ refers to the vertical axis, and $T$ represents the transverse direction perpendicular to the principle plane. $C_{a p p}$ is the apparent propagation velocity which is frequency dependent. When the simultaneous ground rotations and translations are both available, the above relationships can be used to verify the accuracy and appropriateness of elastic plane wave theory to estimate rotational earthquake motions. This has been attempted for long period records of far-field seismic events [34-36], and also to derive the local wave velocities [37, 38]. $C_{a p p}$ is usually assigned a constant value. Various values have been used in research studies, such as $0.6 \mathrm{~km} / \mathrm{s}$ in [39], or $1 \sim 3 \mathrm{~km} / \mathrm{s}$ in [5], $C_{\text {app }}$ is also assumed to be the average site specific shear wave velocity [16, 40-42]. It can be seen from above equations that the rotational components scaled from corresponding translational components are sensitive to the value of $C_{a p p}$ which appears in the denominator and is inversely proportional to the results. Also noted by above equations, the waveforms of rotational velocity and corresponding translational acceleration should be similar under a plane wave propagation assumption.

In our 6DOF data set from GVDA, waveform similarities between rotational and translational components have been noted visually for several events, for instance the far-field Mw7.2 event in Fig. 4. The vertical translational acceleration time series shows similarity to the rocking velocity time series. Fig. 11 compares the waveforms of transverse accelerations and torsional velocity, vertical acceleration and transverse rocking velocity for this $M_{W} 7.2$ event. The rotational components in right-hand Cartesian coordinate system are rotated to a radial-transverse coordinate system according to the axis transformation method provided by Pham et al. [43]. The translational accelerations are normalized by $C_{\text {eqiv }}$ in above equations to have equal peak values with corresponding observed rotational velocities for a convenient comparison of waveforms and Fourier spectrums. $C_{\text {eqiv }}$ represents the equivalent apparent velocity as used in the normalization, since it is not the actual apparent wave propagation velocity (see below for details). 


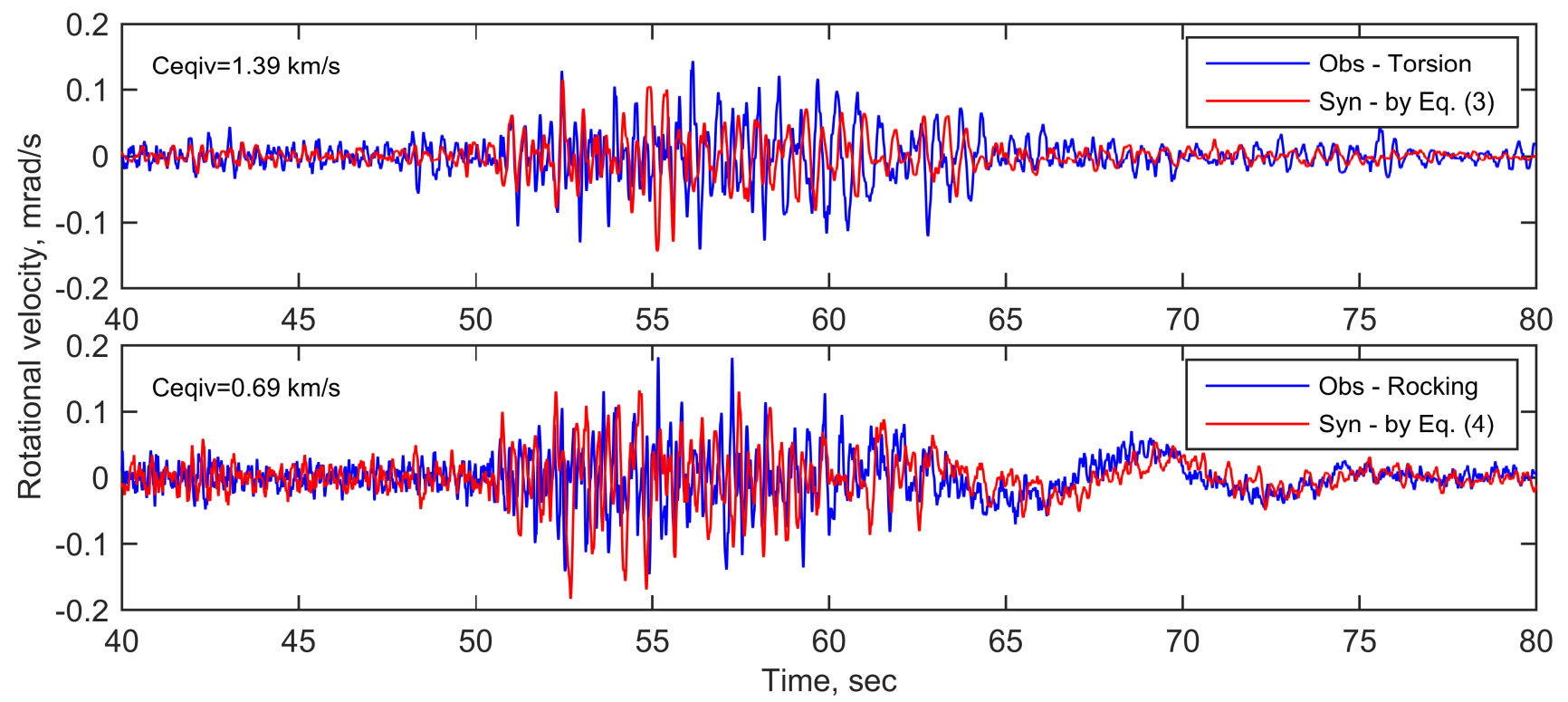

Fig. 11. Waveforms comparison of directly observed rotational components and synthetic rotations from translational components by Eq. (3) and Eq. (4), for the $M_{W} 7.2$ event. The $C_{\text {eqiv }}$ values are chosen to normalize the corresponding synthetics to have same peak value as observed rotations. Above: observed torsion and synthesized torsion from transverse translational acceleration by Eq. (3), $C_{\text {eqiv }}=1.39 \mathrm{~km} / \mathrm{s} ;$ Below: observed rocking component and synthetic rotation from vertical acceleration by Eq. (4), $C_{\text {eqiv }}=0.69 \mathrm{~km} / \mathrm{s}$.
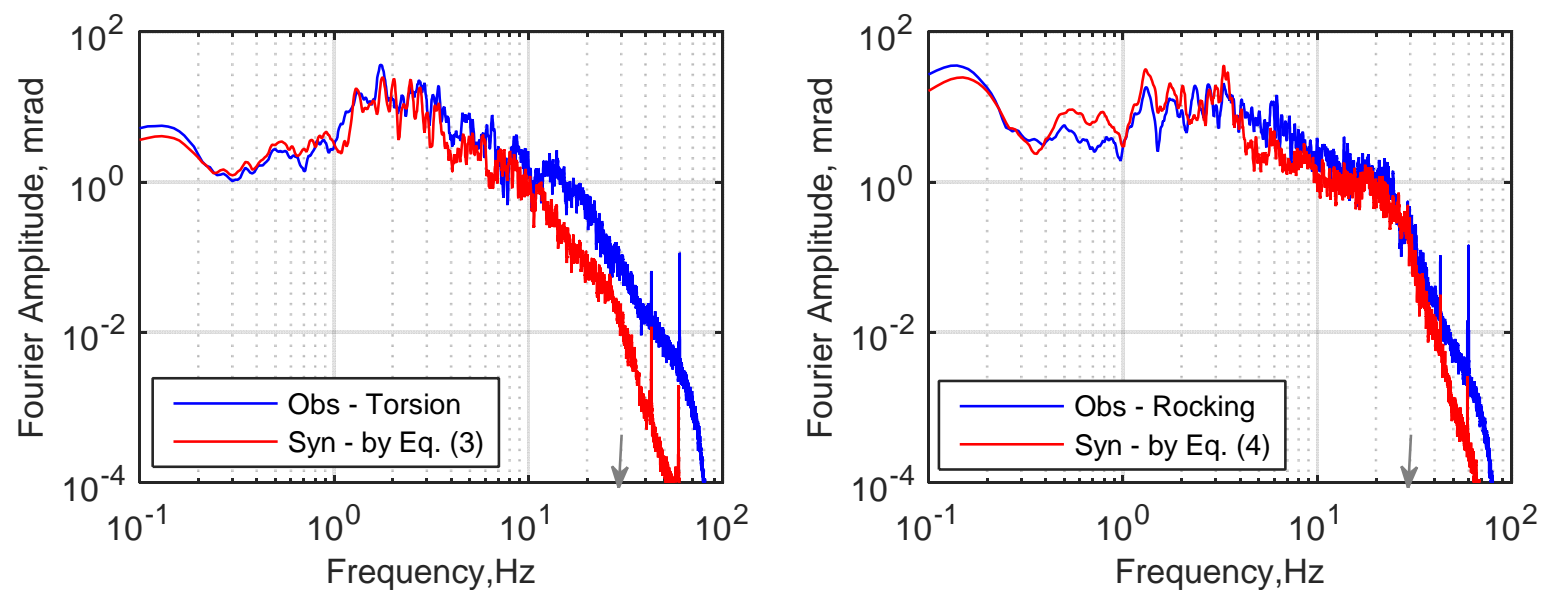

Fig. 12. Fourier amplitude spectra comparison of directly observed rotational components and synthetic rotations from translational components by Eq. (3) and Eq. (4), for the $M_{W} 7.2$ event, The cutoff frequency is denoted by gray arrow on the plots.

As Fig. 11 shows, the rotational velocity waveform does show similarity with the translational waveform for part of the seismogram, especially for long period content, but not for the whole time history. Peak values appear at different times. A frequency domain comparison between the observed rotations and scaled estimations from translational motions, shown in Figure 12, is more favorable. The equivalent apparent velocities $C_{\text {eqiv }}$, used in this normalization process, are different for rocking and torsional components, as $C_{\text {eqiv }}=1.39 \mathrm{~km} / \mathrm{s}$ using Eq (3) to derive torsional component from transverse translational component, and $C_{\text {eqiv }} \sim 0.69 \mathrm{~km} / \mathrm{s}$ using Eq. (4) to derive rocking component form vertical translational component. These values are smaller than the actual apparent wave propagation velocity, $C_{a p p} \sim 2.4 \mathrm{~km} / \mathrm{s}$, obtained by cross-correlation coefficient analysis of the GVDA array records of this event. 
This means that rotational components will be underestimated by 1.7 times smaller for torsional components, and 3.5 times smaller for rocking component for this event if the actual wave propagation velocity were used for estimation. Similar phenomenon for the difference between actual wave propagation velocity and $C_{\text {eqiv }}$ has also been noted by by Spaudich and Fletcher[20], and Smerzini et al.[44] ( $C_{\text {eqiv }}$ refers to scaling factor in their papers).

Furthermore, by employing GVDA 6DOF records and equations (3) and (4) in terms of peak values, $C_{\text {eqiv }}$ for different events are examined in Fig. 13. $C_{\text {eqiv }}$ values vary from $0.2 \mathrm{~km} / \mathrm{s}$ to $1.4 \mathrm{~km} / \mathrm{s}$ with different values for torsional and rocking components. Although the $C_{\text {eqiv }}$ are different for individual events and rotational components, the consistency between frequency content of observed and normalized synthetic rotations using individual $C_{\text {eqiv }}$ is good in both near-and-far-field, see Fig. 12 for the far field Mw7.2 event as an example. The apparent wave propagation velocities for events are calculated by spatial cross-correlation analysis of GVDA linear array records, and travel-time analysis is used alternatively to estimate apparent wave velocities when the cross-correlation analysis method gives unrealistic values. The entire time series are used in the calculation, so the time-frequency dependence of $C_{a p p}$ is not considered.

$C_{a p p}$ calculated for different earthquake events is shown in Fig. 13. $C_{a p p}$ values vary from $1.6 \mathrm{~km} / \mathrm{s}$ to $9.8 \mathrm{~km} / \mathrm{s}$, a sudden increase for near-field earthquake events, which indicates a nearly vertical incidence for this site. A nominal 1 $\mathrm{km} / \mathrm{s}$ apparent wave velocity will mostly underestimate the rotational components, while a site specific shear wave velocity $\left(v_{30} \sim 0.28 \mathrm{~km} / \mathrm{s}\right.$ for GVDA site) will overestimate. Both of these approaches have been used in previous published rotational ground motion estimations. Also seen from Fig. 13, $C_{\text {eqiv }}$ is only weakly dependent on earthquake magnitude or source-to-site distance. It is smaller than the actual apparent wave propagation velocity, especially for near-field condition.

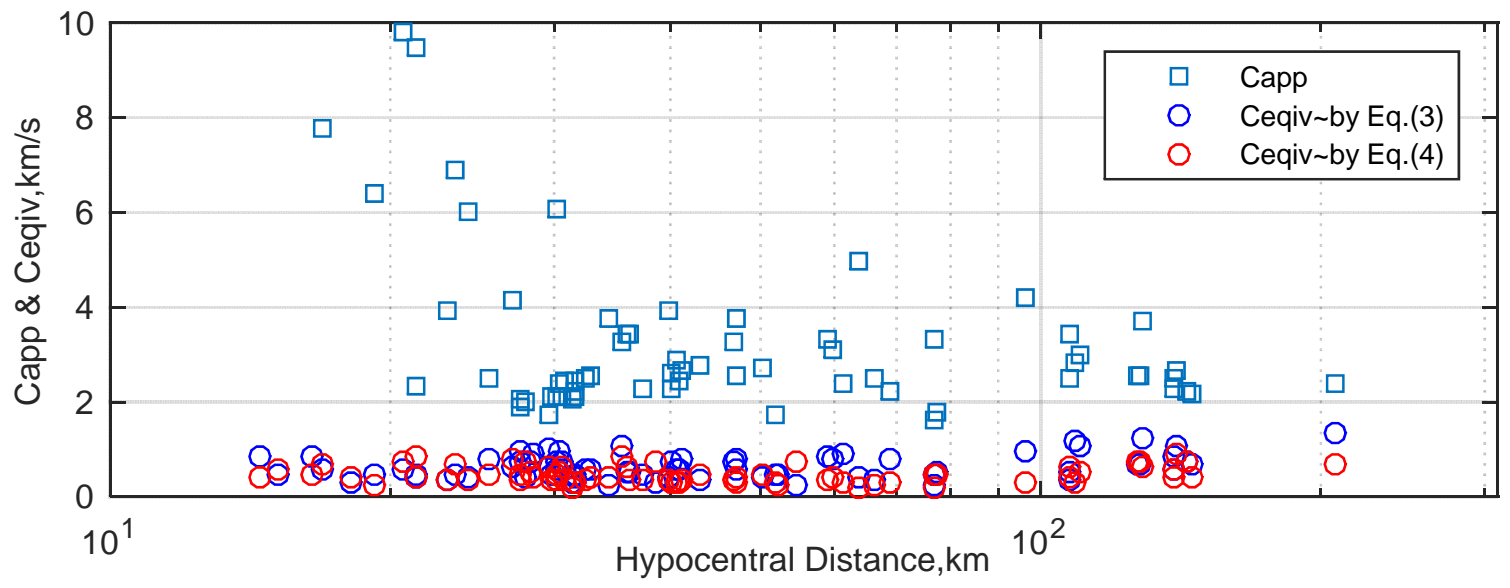

Fig. 13. Apparent wave propagation velocity $\left(C_{a p p}\right)$ and $C_{\text {eqiv }}$ in function of hypocentral distance. $C_{\text {app }}$ is calculated by cross-correlation coefficient analysis of array records or a travel-time analysis. $C_{e q i v}$ is estimated respectively by equations Eq. (3) and Eq. (4) in terms of peak values. The mean and standard deviation values of $C_{\text {eqiv }}$ for Eq. (3): 0.63 $\pm 0.25 \mathrm{~km} / \mathrm{s}$; for Eq.(4): $0.46 \pm 0.18 \mathrm{~km} / \mathrm{s}$, respectively for rocking and torsional components.

As a concluding remark, the differences between $C_{\text {eqiv }}$ (calculated using elastic plane wave equations) and measured apparent wave propagation velocity show that classical elastic plane wave theory may greatly underestimate the ground rotations in both near-and-far field. Care should be taken if equations (3) or (4) are used to generate rotational components from corresponding translational component for engineering application purpose, or are used to estimate local apparent wave velocity from collocated amplitude measurements of translations and rotations. The plane wave assumption may not be valid for generating rotational ground motions, especially close to the source. 


\section{Engineering applications}

As discussed in the Introduction, effects of rotational excitations on structural response have been recognized in historical and recent post-earthquake damage surveys. Rotational ground motions may contribute to structural damage, especially in the near-field region where the structures have been observed rotated or toppled.

Analysis of recorded six-component data in last section indicates potentially larger ground rotations at closer distance from the earthquake source. Short-period structures at close distances may then be expected to experience significant rotational ground motions in addition to strong translational motions. Rotational ground motions contain relatively higher frequencies, so for stiff structures like nuclear power plants and dams more consideration should be given to the effects of rotational input motions. Therefore, it will be necessary to include the rotational ground motion in structural seismic design. Note that, in Eurocode 8 [45], rotational ground motions are already considered for tall, slender structures like towers.

The response spectrum method is a main tool for seismic design when considering translational motion. Extending the response spectrum to rotational ground motion adds a similarly useful tool when considering rotational ground motions in seismic design. Similarly to the translational response spectrum, the rotational response spectrum represents the peak rotational acceleration of a single degree of freedom rotational oscillator as a function of natural period and damping ratio, excited by a prescribed rotational ground acceleration [46].

The relationship between rotational response spectrum and the translational response spectrum has been studied for some earthquakes using elastic wave theory in frequency domain [10, 11, 41, 47]. In Eurocode 8, part 6 (EC8.6) the seismic design of tower-shaped structures includes the rotational spectrum in terms of translational response spectrum [45]. However, this rotational spectrum has not been empirically.

In this section, we use our data set of 6DOF earthquake ground motions to study the rotational response spectrum and its relationship with the translational response spectrum. Fig. 14 shows the 5 percent damped acceleration response spectrum of the $M_{W}$ 7.2 EI Mayor-Cucapah earthquake (eventid 14607652). Note that this is a far-field ground motion record. Among three translational ground motions, two horizontal components are similar to the vertical component in the long periods $(>1 \mathrm{~s})$, while in short periods $(<1 \mathrm{~s})$ the horizontal components are more than double the vertical component. For the three rotational ground motions, rotational response spectrum values are similar in the periods below $1.5 \mathrm{~s}$, but for periods above $1.5 \mathrm{~s}$, the rocking components are larger than the torsional component.
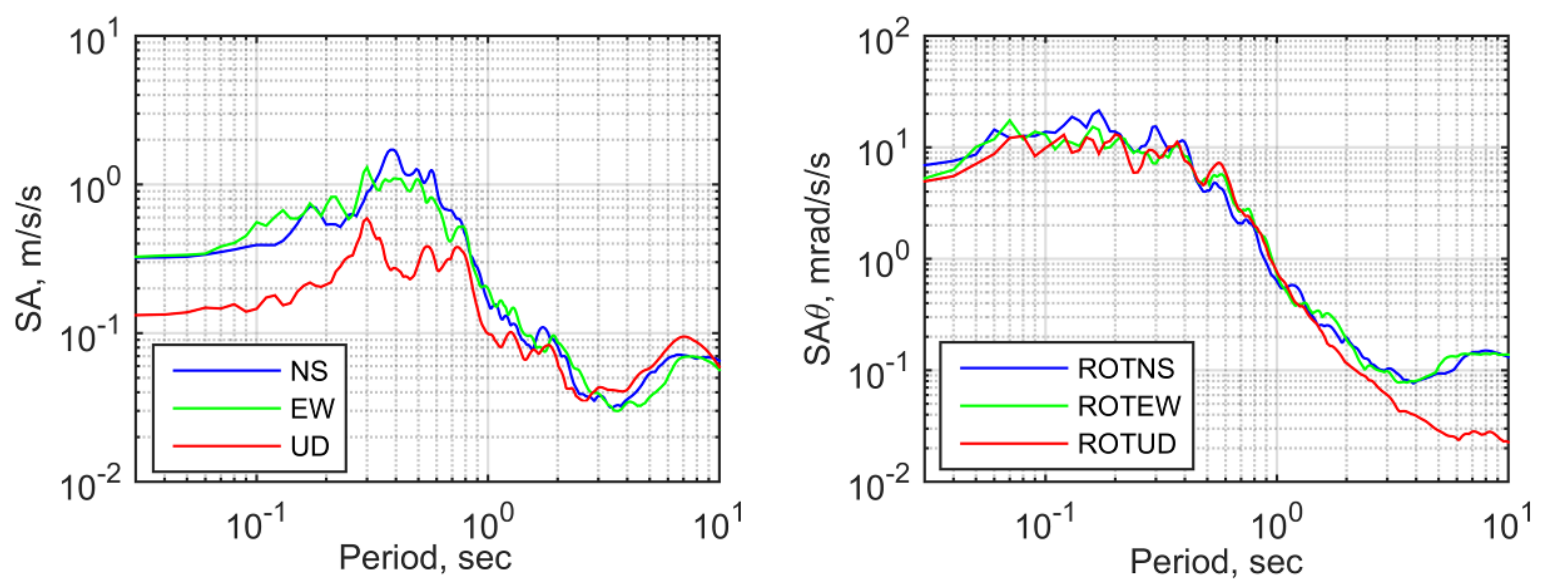

Fig. 14. Response spectrum (5\% damped) of translational and rotational components for the $M_{W} 7.2$ EI MayorCucapah earthquake.

Significant additional rotational strong ground motion records will likely not be available in the near future. The existing research on estimating rotational ground motion in terms of corresponding translational ground motions, including the work in this paper, has improved the understanding of rotational components due to earthquakes. In this 
context it is meaningful to further study the possibility of estimating rotational response spectra from translational response spectra.

For the GVDA data set, the response spectral ratios of rocking and torsional components to horizontal components for all the recordings are shown in Figure 15. When calculating this spectral ratio, the two horizontal components and two rocking components are considered independently. There is considerable variability (as is always the case for empirical ground motions), but the trend is clear for the GVDA data set. For both rocking and torsional components, the translation/rotation ratio shows a relatively flat region at high frequency (above $10 \mathrm{~Hz} / \mathrm{below} 0.1 \mathrm{sec}$ ) and decreases with increasing period. When compared with the definition of rotational spectrum in Eurocode 8, it is found that EC8.6 is about double the average spectra ratio here and gives larger torsion than rocking components.
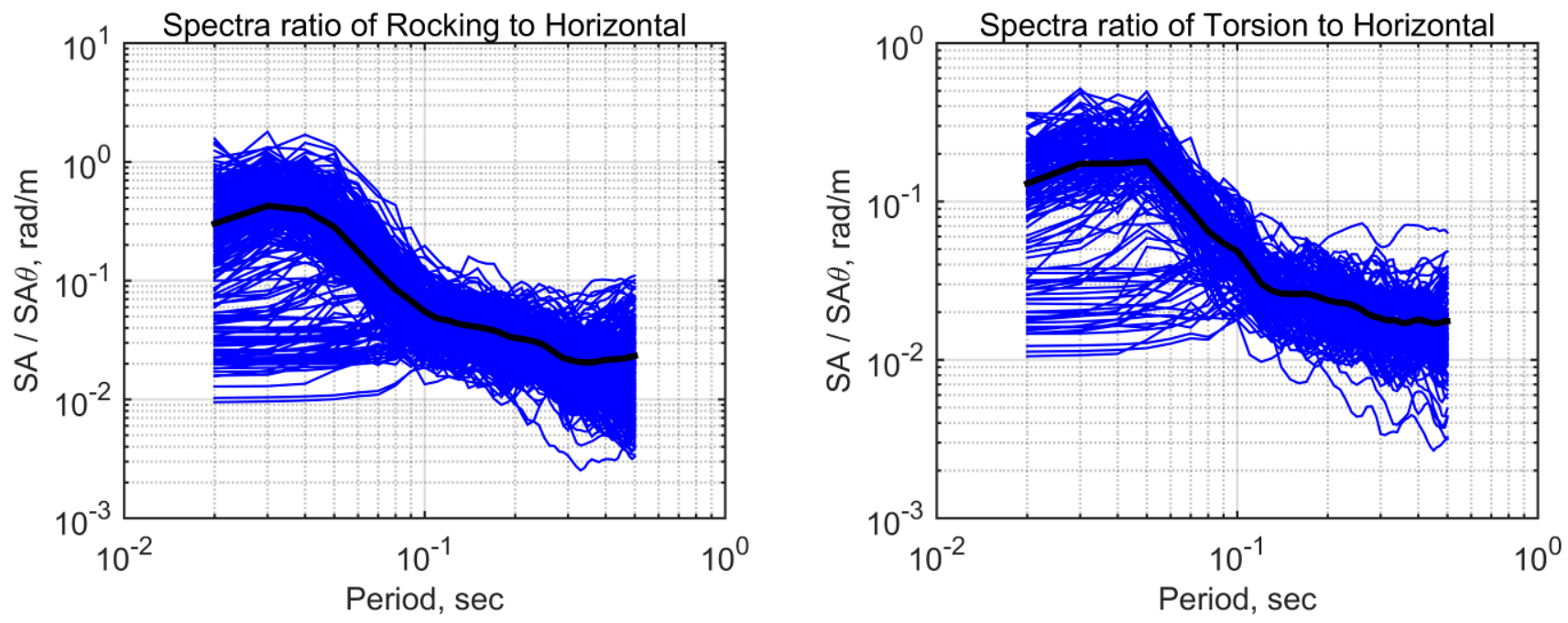

Fig. 15. Ratio of 5\% damped response spectra of rocking and torsional acceleration to that of horizontal acceleration for the recorded earthquake events, the thick black line is the mean of them.

To make the result more applicable in engineering practice, assume the response spectrum of free-field rotational ground motions can be written as:

$$
S A \theta(T)=\phi(T) S A(T)
$$

where $\phi(T)$ is the ratio of rotational response spectrum to translational response spectra. This shape function converts (in an averaged sense) the corresponding translational response spectrum to rotational response spectrum. Figure 16 shows the spectra ratio for three common design damping ratio: $2 \%, 5 \%$ and $10 \%$. As shown, the difference is not significant for different damping ratio. In Equation 6 below we give $\phi(T)$, derived by least squares fitting the mean curve in Figure 16 in two segments.

$$
\phi(T)= \begin{cases}0.015+0.01 / T \leq 0.5 & (\text { rocking }) \\ 0.015+0.005 / T \leq 0.2 & \text { (torsion) }\end{cases}
$$

Of course, this single-station empirical $\phi(T)$ might be different for different sets of source, path, and site conditions. Further 6DOF ground motion measurements at this station and at other stations will be needed to develop statistically stable shape functions for Eurocode validation and for other rotational response spectrum applications. 


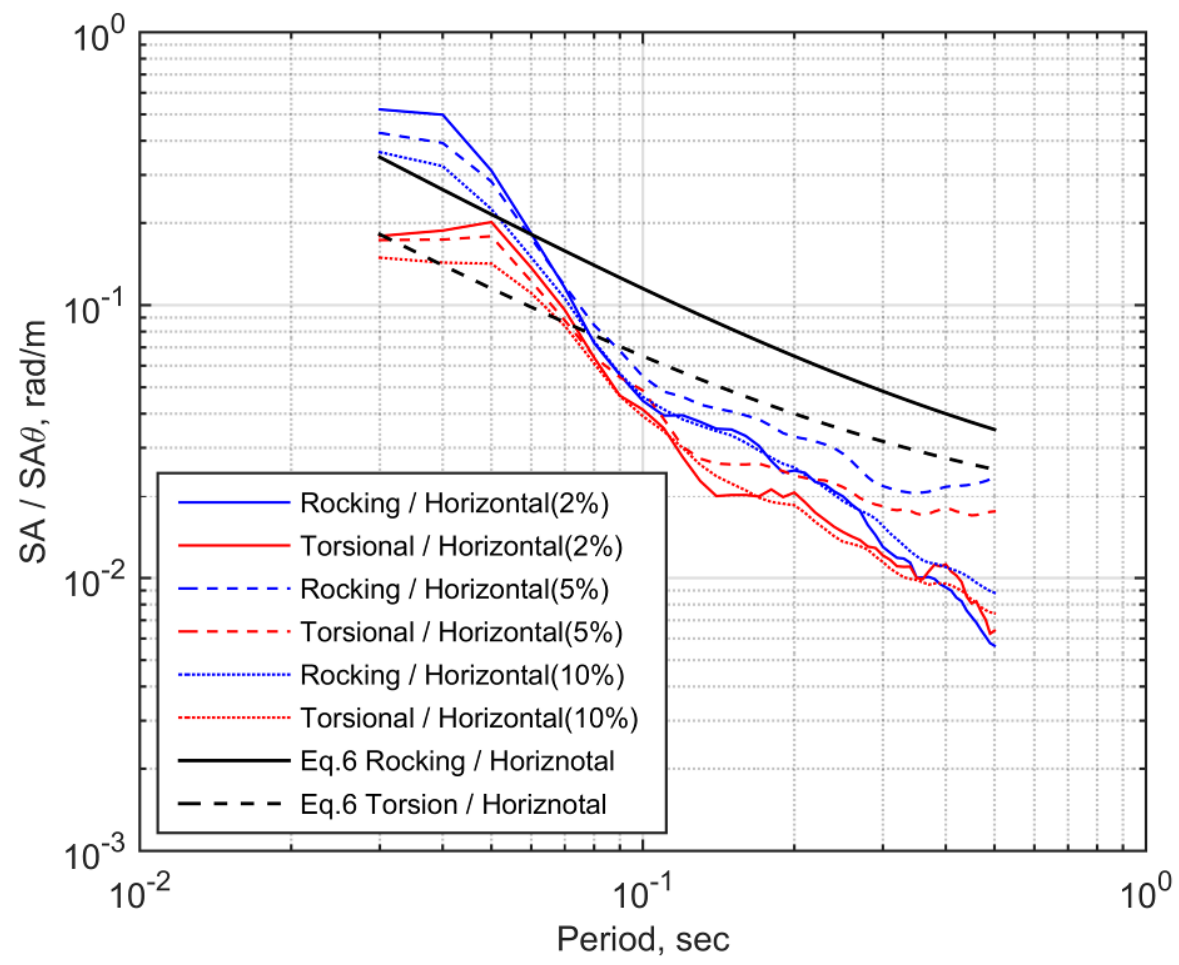

Fig. 16. Averaged ratio of response spectra (damping ratio: $2 \%, 5 \%, 10 \%$ ) of rocking and torsional acceleration to that of horizontal acceleration for the recorded earthquake events.

\section{Conclusions}

At the GVDA array a rotational strong motion triaxial velocity sensor is deployed along with the array of conventional triaxial translational accelerometers. In this paper, 6DOF free-field ground motions with good signal quality from 74 earthquake events with a wide range of hypocentral distances and magnitudes are described. This empirical 6DOF data set was analyzed to investigate the engineering characteristics of free-field rotational ground motions. Sensor response was deconvolved in a standardized manner and recorded rotational velocity time series were differentiated to rotational acceleration in the frequency domain to allow direct amplitude- and phase-corrected comparison of rotational and translational motions from the two types of ground motion sensors. Results of initial analyses of this data set can be summarized as follows:

(1) Six-component ground motions recorded at GVDA show a similar linear relationship between PRV and PGA as suggested by previous observations at Taiwan's HGSD station. However, at GVDA the rocking components are larger than torsional components for most earthquake events, while at HGSD in Taiwan the torsion was generally larger than the rocking components. This is likely attributed to the different types of source and site conditions.

(2) By comparing PRA and PGA, the ratios of PRA to PGA as a function of hypocentral distance was analyzed. Results show relatively larger ground rotations at closer distance, and that the rotational ground motions attenuate much more rapidly than translational ground motions along with distance. Measured rotational ground motions indicate higher frequency content than translational ground motions. Among the rotational components, the rocking components attenuates more rapidly than the torsional component. Exponential functions were fitted to represent the trend of the ratios of PRA to PGA, which could be used preliminarily estimate rotational ground motions when combined with traditional attenuation pattern of horizontal ground motion. The engineering importance of this observation is that short-period structures in the near-field of earthquake shaking may experience significant rotational ground motions in addition to strong translational motions. 
(3) Comparison of directly recorded ground rotations with those calculated from translational motions using elastic wave theory shows large differences in both near-field and far-field recordings. Care should be taken if simple plane wave approximation is used to generate rotational components from corresponding translational component for engineering application purpose, or is used to estimate local apparent wave velocity from collocated amplitude measurements of translations and rotations. In the near-field, plane-wave theory will likely underestimate rotational motions as is observed with this data set.

(4) Rotational response spectra are a useful tool for using roational ground motions in seismic analysis and design. In this study, response spectra of rotational ground accelerations was calculated for different damping ratios and compared with response spectrum of translational ground accelerations. The spectral ratios of rocking and torsional spectra to the corresponding horizontal spectra were analyzed and used to develop a shape function to estimate rotational response spectrum from a translational response spectrum.

Finally, it should be emphasized that the recorded data here are limited in amount and represent a single-station site condition. Also, the limited bandwidth of six-component recordings of these mostly small earthquakes limits the frequency range of this data set. To establish robust ground motion prediction equations for rotational components and to develop rotational response spectra for design will require more observations, especially spatially distributed recordings for more significant earthquakes.

\section{Acknowledgements}

We are grateful to the NEES@UCSB staff for operating the GVDA array and the rotational sensors, and for their assistance with the recorded data. The NEES@UCSB effort was supported by the U.S. National Science Foundation under Grant CMMI-0927178. Thanks go to China Scholarship Council for financially supporting the first author's two year joint research at UCLA, and the authors would like to acknowledge the support from China National Science and Technology Support Program (grant number 2015BAK17B04) and China Major Research Projects of National Natural Science Fund-Integration Program (grant number 91315301).

\section{References:}

[1] W.H.K. Lee, M. Celebi, M.I. Todorovska, H. Igel. Introduction to the Special Issue on Rotational Seismology and Engineering Applications. Bull Seismol Soc Am 2009; 99: 945-57.

[2] G.C. Hart, M. Lew, J. Roger M. Dijulio. Torsional Response of High-Rise Buildings. Journal of the Structural Division 1975; 101: 397-416.

[3] J.C. De la Llera, A.K. Chopra. Accidental torsion in buildings due to base rotational excitation. Earthq Eng Struct Dyn 1994; 23: $1003-21$.

[4] M.R. Ghayamghamian, G.R. Nouri, H. Igel. The Effect of Torsional Ground Motion on Structural Response: Code Recommendation for Accidental Eccentricity. Bull Seismol Soc Am 2009; 99: 1261-70.

[5] M.D. Trifunac. The role of strong motion rotations in the response of structures near earthquake faults. Soil Dyn Earthq Eng 2009; 29: 382-93.

[6] J.T. Kozak. Tutorial on Earthquake Rotational Effects: Historical Examples. Bull Seismol Soc Am 2009; 99: 998-1010.

[7] L. Cucci, A. Tertulliani. The Earthquake-Rotated Objects Induced by the 2012 Emilia (Northern Italy) Seismic Sequence: Relation with Seismological and Geomorphological Factors. Seismol Res Lett 2013; 84: 973-81.

[8] L. Cucci, A. Tertulliani. Clues for a Relation between Rotational Effects Induced by the 2009 Mw 6.3 L' Aquila (Central Italy) Earthquake and Site and Source Effects. Bull Seismol Soc Am 2011; 101: 1109-20.

[9] S.L. Sargeant, R.M. Musson. Short note: Rotational earthquake effects in the United Kingdom. Bull Seismol Soc Am 2009; 99 : 1475-79.

[10] V.W. Lee, M.D. Trifunac. Torsional accelerograms. International Journal of Soil Dynamics and Earthquake Engineering 1985; 4: 132-39.

[11] V.W. Lee, M.D. Trifunac. Rocking strong earthquake accelerations. Soil Dyn Earthq Eng 1987; 6: 75-89.

[12] D. Basu, A.S. Whittaker, M.C. Constantinou. Estimating Rotational Components of Ground Motion Using Data Recorded at a Single Station. J Eng Mech 2012; 138: 1141-56.

[13] M. Takeo. Ground rotational motions recorded in near-source region of earthquakes. Geophys Res Lett 1998; $25:$ 789-92. 
[14] C. Liu, B. Huang, W.H.K. Lee. Observing Rotational and Translational Ground Motions at the HGSD Station in Taiwan from 2007 to 2008. Bull Seismol Soc Am 2009; 99: 1228.

[15] D. Basu, A.S. Whittaker, M.C. Constantinou. Extracting rotational components of earthquake ground motion using data recorded at multiple stations., Southern Gate, Chichester, West Sussex, PO19 8SQ, United Kingdom, 2013. pp. 451-68.

[16] A. Castellani, G. Boffi. Rotational components of the surface ground motion during an earthquake. Earthq Eng Struct Dyn 1986; 14: 751-67.

[17] W. Chi, W.H.K. Lee, C.J. Lin, C.C. Liu. Inverting ground motion from a seismometer array to obtain the vertical component of rotation: A test using data from explosions. J Asian Earth Sci 2013; 66: 55-62.

[18] B. Huang. Ground rotational motions of the 1999 Chi-Chi, Taiwan earthquake as inferred from dense array observations. Geophys Res Lett 2003; 30: 1307.

[19] C.S. Oliveira, B.A. Bolt. Rotational components of surface strong ground motion. Earthq Eng Struct Dyn 1989; 18: 517-26.

[20] P. Spudich, J.B. Fletcher. Observation and Prediction of Dynamic Ground Strains, Tilts, and Torsions Caused by the Mw 6.0 2004 Parkfield, California, Earthquake and Aftershocks, Derived from UPSAR Array Observations. Bull Seismol Soc Am 2008; 4: 1898-914.

[21] W. Suryanto, H. Igel, J. Wassermann, A. Cochard, B. Schuberth, D. Vollmer, F. Scherbaum, U. Schreiber, A. Velikoseltsev. First Comparison of Array-Derived Rotational Ground Motions with Direct Ring Laser Measurements. Bull Seismol Soc Am 2006; 96: 2059-71.

[22] P. Spudich, L.K. Steck, M. Hellweg, J.B. Fletcher. Transient stresses at Parkfield, California, produced by the M 7.4 Landers earthquake of June 28, 1992: Observations from the UPSAR dense seismograph array. J Geophys Res 1995; 100: 675-90.

[23] R.L. Nigbor. Six-degree-of-freedom ground-motion measurement. Bull Seismol Soc Am 1994; 84: 1665-69.

[24] W. Lee, B.S. Huang, C.A. Langston, C.J. Lin, C.C. Liu, T.C. Shin, T.L. Teng, C.F. Wu. Review: Progress in Rotational Ground-Motion Observations from Explosions and Local Earthquakes in Taiwan. Bull Seismol Soc Am 2009; 99: 958-67.

[25] T.L. Youd, J.H. Steidl, R.L. Nigbor. Lessons Learned and Need for Instrumented Liquefaction Sites. Soil Dyn Earthq Eng 2004; 24: 639-46.

[26] J.H. Steidl, F. Civilini, S. Seale. What have we learned after a decade of experiments and monitoring at the NEES@UCSB permanently instrumented field sites?. 10NCEE, Alaska, 2014.

[27] R.L. Nigbor, J.R. Evans, C.R. Hutt. Laboratory and Field Testing of Commercial Rotational Seismometers. Bull Seismol Soc Am 2009; 99: 1215-27.

[28] U.S.G.S. Survey. Quaternary fault and fold database for the United States. 2006.

[29] T.D. Ancheta, R.B. Darragh, J.P. Stewart, E. Seyhan, W.J. Silva, B.S.J. Chiou, K.E. Wooddell, R.W. Graves, A.R. Kottke, D.M. Boore, T. Kishida, J.L. Donahue. PEER NGA-West2 Database. Pacific Earthquake Engineering Research center Headquarters at the University of California, Barkeley2013. pp. 83-84.

[30] D.M. Boore, J.J. Bommer. Processing of strong-motion accelerograms: needs, options and consequences. Soil Dyn Earthq Eng 2005; 25: 93-115.

[31] M. Takeo. Rotational Motions Observed during an Earthquake Swarm in April 1998 Offshore Ito, Japan. Bull Seismol Soc Am 2009; 99: 1457.

[32] H.B. Seed, I.M. Idriss. Ground motions and soil liquefaction during earthquakes. Earthquake Engineering Research Institute, Berkeley, California, 1982.

[33] R.K. McGuire. Seismic Ground Motion Parameter Relationns. Journal of the Geotechnical Engineering Division 1978; 104: 481-90.

[34] H. Igel, A. Cochard, J. Wassermann, A. Flaws, U. Schreiber, A. Velikoseltsev, N. Pham Dinh. Broad-band observations of earthquake-induced rotational ground motions. Geophys J Int 2007; 168: 182-96.

[35] C. Lin, H. Huang, N.D. Pham, C. Liu, W. Chi, W.H.K. Lee. Rotational motions for teleseismic surface waves. Geophys Res Lett 2011; 38: L15301.

[36] H. Igel, U. Schreiber, A. Flaws, B. Schuberth, A. Velikoseltsev, A. Cochard. Rotational motions induced by the M8. 1 Tokachi-oki earthquake, September 25, 2003. Geophys Res Lett 2005; 32: L8309.

[37] D. Kurrle, H. Igel, A.M.G. Ferreira, J. Wassermann, U. Schreiber. Can we estimate local Love wave dispersion properties from collocated amplitude measurements of translations and rotations? Geophys Res Lett 2010; 37: L4307.

[38] C. Hadziioannou, P. Gaebler, U. Schreiber, J. Wassermann, H. Igel. Examining ambient noise using colocated measurements of rotational and translational motion. J Seismol 2012; 16: 787-96.

[39] M.R. Falamarz-Sheikhabadi. Simplified relations for the application of rotational components to seismic design codes. Eng Struct 2014; 59: 141-52.

[40] M.R. Falamarz-Sheikhabadi, M. Ghafory-Ashtiany. Approximate formulas for rotational effects in earthquake engineering. J Seismol 2012; 16: 815-27.

[41] W.K. Tso, T. Hsu. Torsional spectrum for earthquake motions. Earthq Eng Struct Dyn 1978; 6: 375-82.

[42] N.M. Newmark. Torsion in symmetrical buildings. 4WCEE, Santiago,Chile, 1969. 
[43] N.D. Pham, H. Igel, J. Wassermann, A. Cochard, U. Schreiber. The Effects of Tilt on Interferometric Rotation Sensors. Bull Seismol Soc Am 2009; 99: 1352-65.

[44] C. Smerzini, R. Paolucci, M. Stupazzini. Experimental and Numerical Results on Earthquake-Induced Rotational Ground Motions. J Earthq Eng 2009; S1: 66-82.

[45] E.C.F. Standardization. Eurocode 8, Design of structures for earthquake resistance, Part 6: Towers, masts, and chimneys. 2005.

[46] A. Castellani, M. Stupazzini, R. Guidotti. Free-field rotations during earthquakes: Relevance on buildings. Earthq Eng Struct Dyn 2012; 41: 875-91.

[47] V.W. Lee, M.D. Trifunac. Empirical Scaling of Rotational Spectra of Strong Earthquake Ground Motion. Bull Seismol Soc Am 2009; 99: 1378. 
Table. 1. List of Earthquakes with 6DOF Ground Motions Recorded in GVDA from 11 October 2008 to 30 December2014

\begin{tabular}{|c|c|c|c|c|c|c|c|c|c|c|c|c|}
\hline UID & EVENTID & Date \& Time & $\begin{array}{c}\text { Magnitude } \\
\left(\mathrm{M}_{\mathrm{L}}\right)\end{array}$ & $\begin{array}{l}\text { Depth } \\
(\mathrm{km})\end{array}$ & $\begin{array}{l}\text { Distance } \\
(\mathrm{km})\end{array}$ & $\begin{array}{c}\text { Azimuth } \\
\left({ }^{\circ}\right)\end{array}$ & $\begin{array}{l}\text { Latitude } \\
\left(^{\circ}\right)\end{array}$ & $\begin{array}{l}\text { Longitude } \\
\left(^{\circ}\right)\end{array}$ & $\begin{array}{c}\text { PGA- } \\
\text { vertical } \\
(\mathrm{m} / \mathrm{s} / \mathrm{s}) \\
\end{array}$ & $\begin{array}{c}\text { PGA- } \\
\text { horizontal } \\
(\mathrm{m} / \mathrm{s} / \mathrm{s})\end{array}$ & $\begin{array}{c}\text { PRV- } \\
\text { torsion } \\
(\mathrm{mrad} / \mathrm{s})\end{array}$ & $\begin{array}{l}\text { PRV- } \\
\text { rocking } \\
(\mathrm{mrad} / \mathrm{s}) \\
\end{array}$ \\
\hline 18237 & 14995172 & 2011-06-03 05:45:24 (UTC) & 3.1 & 12.9 & 14.5 & 236 & 33.636 & -116.732 & 0.130 & 0.150 & 0.096 & 0.349 \\
\hline 6637 & 14491232 & 2009-07-26 04:54:04 (UTC) & 3.5 & 14.0 & 15.2 & 227 & 33.633 & -116.719 & 0.314 & 0.420 & 0.453 & 0.700 \\
\hline 20744 & 11327386 & 2013-06-28 17:45:48 (UTC) & 3.4 & 15.6 & 16.5 & 203 & 33.624 & -116.696 & 0.196 & 0.232 & 0.156 & 0.462 \\
\hline 8712 & 10353485 & 2008-10-11 19:33:59 (UTC) & 3.0 & 16.5 & 16.9 & 274 & 33.671 & -116.714 & 0.100 & 0.116 & 0.101 & 0.162 \\
\hline 20394 & 15332633 & 2013-04-25 18:59:44 (UTC) & 3.1 & 16.9 & 18.2 & 248 & 33.646 & -116.740 & 0.115 & 0.097 & 0.149 & 0.306 \\
\hline 18259 & 15001500 & 2011-06-14 08:25:41 (UTC) & 3.6 & 18.1 & 19.3 & 291 & 33.690 & -116.740 & 0.076 & 0.156 & 0.139 & 0.361 \\
\hline 26526 & 11407682 & 2013-12-30 23:44:21 (UTC) & 3.6 & 19.6 & 20.6 & 122 & 33.700 & -116.733 & 0.163 & 0.135 & 0.126 & 0.311 \\
\hline 18917 & 15217865 & 2012-09-18 21:09:40 (UTC) & 3.0 & 20.3 & 21.3 & 295 & 33.694 & -116.737 & 0.076 & 0.095 & 0.107 & 0.201 \\
\hline 8736 & 10357093 & 2008-10-30 17:09:40 (UTC) & 3.2 & 13.0 & 21.3 & 149 & 33.539 & -116.578 & 0.044 & 0.076 & 0.063 & 0.092 \\
\hline 18004 & 10891517 & 2011-02-12 17:30:44 (UTC) & 3.6 & 17.2 & 23.0 & 285 & 33.704 & -116.832 & 0.057 & 0.051 & 0.062 & 0.175 \\
\hline 18987 & 15237073 & 2012-10-28 07:47:03 (UTC) & 3.9 & 19.4 & 23.5 & 281 & 33.692 & -116.813 & 0.130 & 0.106 & 0.097 & 0.261 \\
\hline 18673 & 15139881 & 2012-04-24 19:44:10 (UTC) & 3.3 & 18.1 & 24.3 & 287 & 33.712 & -116.840 & 0.045 & 0.045 & 0.053 & 0.136 \\
\hline 18458 & 11035389 & 2011-11-22 14:39:44 (UTC) & 3.1 & 8.9 & 25.6 & 159 & 33.468 & -116.580 & 0.010 & 0.014 & 0.009 & 0.025 \\
\hline 19125 & 10783581 & 2010-08-21 13:59:46 (UTC) & 3.6 & 12.9 & 27.1 & 356 & 33.882 & -116.693 & 0.040 & 0.044 & 0.036 & 0.085 \\
\hline 25674 & 11368274 & 2013-09-22 13:10:11 (UTC) & 3.4 & 13.5 & 27.6 & 164 & 33.461 & -116.603 & 0.032 & 0.070 & 0.031 & 0.090 \\
\hline 4723 & 14733020 & 2010-06-03 08:44:14 (UTC) & 3.2 & 7.0 & 27.6 & 133 & 33.505 & -116.463 & 0.014 & 0.027 & 0.021 & 0.042 \\
\hline 19599 & 15302289 & 2013-03-13 04:21:14 (UTC) & 3.4 & 11.8 & 27.9 & 133 & 33.513 & -116.475 & 0.032 & 0.022 & 0.028 & 0.045 \\
\hline 8848 & 14403732 & 2008-11-17 12:35:42 (UTC) & 4.1 & 12.2 & 28.4 & 223 & 33.500 & -116.861 & 0.189 & 0.237 & 0.153 & 0.348 \\
\hline 8850 & 14403792 & 2008-11-17 17:41:37 (UTC) & 3.8 & 11.5 & 28.6 & 223 & 33.496 & -116.864 & 0.073 & 0.114 & 0.068 & 0.189 \\
\hline 7191 & 10497645 & 2009-11-16 13:54:34 (UTC) & 3.6 & 8.0 & 29.6 & 173 & 33.415 & -116.635 & 0.002 & 0.007 & 0.003 & 0.004 \\
\hline 19540 & 11273498 & 2013-03-27 17:50:29 (UTC) & 3.4 & 8.5 & 29.9 & 132 & 33.495 & -116.445 & 0.016 & 0.024 & 0.033 & 0.047 \\
\hline 19542 & 11273634 & 2013-03-27 18:17:00 (UTC) & 3.7 & 8.8 & 30.1 & 132 & 33.495 & -116.443 & 0.042 & 0.062 & 0.050 & 0.114 \\
\hline 18314 & 15017980 & 2011-07-15 12:03:12 (UTC) & 3.1 & 15.2 & 30.1 & 292 & 33.755 & -116.934 & 0.013 & 0.017 & 0.012 & 0.028 \\
\hline 19574 & 15296281 & 2013-03-11 16:56:06 (UTC) & 4.7 & 13.1 & 30.3 & 133 & 33.502 & -116.457 & 0.222 & 0.471 & 0.219 & 0.488 \\
\hline 18278 & 10982077 & 2011-07-26 17:42:13 (UTC) & 3.1 & 14.8 & 30.6 & 141 & 33.481 & -116.492 & 0.009 & 0.018 & 0.011 & 0.015 \\
\hline 18651 & 11092194 & 2012-04-12 18:53:01 (UTC) & 3.5 & 7.7 & 30.8 & 140 & 33.464 & -116.466 & 0.010 & 0.017 & 0.014 & 0.033 \\
\hline 18135 & 10926101 & 2011-04-15 11:48:56 (UTC) & 3.0 & 5.8 & 31.4 & 138 & 33.462 & -116.451 & 0.004 & 0.007 & 0.009 & 0.020 \\
\hline 4901 & 10748837 & 2010-07-12 05:50:29 (UTC) & 3.3 & 9.1 & 31.5 & 135 & 33.478 & -116.442 & 0.023 & 0.063 & 0.077 & 0.077 \\
\hline 18720 & 15152625 & 2012-05-21 06:19:59 (UTC) & 3.4 & 15.5 & 31.6 & 141 & 33.476 & -116.487 & 0.035 & 0.094 & 0.105 & 0.118 \\
\hline 18134 & 10926085 & 2011-04-15 11:47:26 (UTC) & 3.2 & 5.0 & 31.6 & 137 & 33.462 & -116.445 & 0.006 & 0.007 & 0.012 & 0.024 \\
\hline 4856 & 10738357 & 2010-07-08 02:34:36 (UTC) & 3.4 & 12.9 & 32.4 & 142 & 33.458 & -116.476 & 0.010 & 0.028 & 0.019 & 0.037 \\
\hline 18431 & 15059420 & 2011-10-05 07:36:19 (UTC) & 3.2 & 14.7 & 32.8 & 136 & 33.479 & -116.454 & 0.030 & 0.039 & 0.036 & 0.075 \\
\hline 3427 & 14603204 & 2010-03-21 15:30:00 (UTC) & 3.0 & 15.0 & 34.3 & 349 & 33.941 & -116.736 & 0.032 & 0.033 & 0.038 & 0.117 \\
\hline 4827 & 10166242 & 2010-07-07 23:53:34 (UTC) & 5.4 & 14.0 & 35.4 & 148 & 33.420 & -116.489 & 0.391 & 1.202 & 0.428 & 0.576 \\
\hline 25296 & 11337786 & 2013-07-22 01:59:48 (UTC) & 3.2 & 18.3 & 36.0 & 349 & 33.942 & -116.736 & 0.039 & 0.025 & 0.019 & 0.070 \\
\hline 17969 & 10866637 & 2011-01-03 11:38:12 (UTC) & 3.3 & 12.7 & 36.1 & 301 & 33.825 & -116.986 & 0.025 & 0.031 & 0.035 & 0.061 \\
\hline 4849 & 10737309 & 2010-07-08 01:07:11 (UTC) & 3.0 & 12.4 & 37.2 & 135 & 33.445 & -116.406 & 0.006 & 0.013 & 0.011 & 0.016 \\
\hline 18248 & 14996388 & 2011-06-05 13:53:20 (UTC) & 3.1 & 12.5 & 38.6 & 16 & 33.984 & -116.562 & 0.009 & 0.008 & 0.010 & 0.028 \\
\hline 20588 & 15343017 & 2013-05-15 16:20:05 (UTC) & 3.1 & 17.9 & 40.0 & 346 & 33.980 & -116.767 & 0.010 & 0.011 & 0.012 & 0.031 \\
\hline 4747 & 14749724 & 2010-06-15 16:23:44 (UTC) & 3.0 & 11.4 & 40 & 323 & 33.395 & -116.422 & 0.008 & 0.013 & 0.011 & 0.046 \\
\hline
\end{tabular}


Table. 1. Continued

\begin{tabular}{|c|c|c|c|c|c|c|c|c|c|c|c|c|}
\hline UID & EVENTID & Date \& Time & $\begin{array}{c}\text { Magnitude } \\
\left(\mathrm{M}_{\mathrm{L}}\right)\end{array}$ & $\begin{array}{c}\text { Depth } \\
(\mathrm{km})\end{array}$ & $\begin{array}{l}\text { Distance } \\
(\mathrm{km})\end{array}$ & $\begin{array}{l}\text { Azimuth } \\
\left(^{\circ}\right)\end{array}$ & $\begin{array}{l}\text { Latitude } \\
\left(^{\circ}\right)\end{array}$ & $\begin{array}{l}\text { Longitude } \\
\left(^{(}\right)\end{array}$ & $\begin{array}{c}\text { PGA- } \\
\text { vertical } \\
(\mathrm{m} / \mathrm{s} / \mathrm{s}) \\
\end{array}$ & $\begin{array}{c}\text { PGA- } \\
\text { horizontal } \\
(\mathrm{m} / \mathrm{s} / \mathrm{s}) \\
\end{array}$ & $\begin{array}{c}\text { PRV- } \\
\text { torsion } \\
(\mathrm{mrad} / \mathrm{s})\end{array}$ & $\begin{array}{c}\text { PRV- } \\
\text { rocking } \\
(\mathrm{mrad} / \mathrm{s})\end{array}$ \\
\hline 19243 & 14883716 & 2010-11-19 00:56:55 (UTC) & 3.8 & 12.8 & 40.0 & 143 & 33.388 & -116.418 & 0.008 & 0.013 & 0.011 & 0.046 \\
\hline 4699 & 10701413 & 2010-06-13 03:09:20 (UTC) & 4.2 & 5.6 & 40.6 & 140 & 33.392 & -116.395 & 0.044 & 0.145 & 0.145 & 0.160 \\
\hline 19265 & 10861101 & 2010-12-23 03:39:36(UTC) & 3.2 & 7.2 & 40.9 & 145 & 33.372 & -116.45 & 0.009 & 0.016 & 0.012 & 0.030 \\
\hline 4698 & 10701405 & 2010-06-13 03:08:57 (UTC) & 4.9 & 12.5 & 41.2 & 143 & 33.383 & -116.416 & 0.003 & 0.011 & 0.005 & 0.007 \\
\hline 8854 & 14404564 & 2008-11-20 21:17:23 (UTC) & 3.2 & 17.5 & 46.7 & 329 & 34.003 & -116.912 & 0.002 & 0.006 & 0.004 & 0.007 \\
\hline 7189 & 10497213 & 2009-11-15 07:54:23 (UTC) & 3.3 & 13.5 & 46.9 & 307 & 33.914 & -117.059 & 0.005 & 0.012 & 0.011 & 0.015 \\
\hline 18717 & 15150785 & 2012-05-18 10:37:12 (UTC) & 3.6 & 7.5 & 47.0 & 147 & 33.319 & -116.402 & 0.005 & 0.011 & 0.008 & 0.017 \\
\hline 25647 & 11359338 & 2013-09-04 04:04:54 (UTC) & 3.2 & 14.5 & 50.1 & 151 & 33.292 & -116.422 & 0.005 & 0.007 & 0.006 & 0.014 \\
\hline 18386 & 11006189 & 2011-09-14 14:44:51 (UTC) & 4.1 & 16.9 & 51.7 & 310 & 33.953 & -117.076 & 0.020 & 0.048 & 0.033 & 0.064 \\
\hline 18642 & 11088434 & 2012-04-04 01:12:09 (UTC) & 3.5 & 2.4 & 52.2 & 66 & 33.858 & -116.157 & 0.004 & 0.006 & 0.006 & 0.018 \\
\hline 18811 & 11135362 & 2012-07-12 17:54:29 (UTC) & 3.9 & 10.8 & 54.7 & 29 & 34.090 & -116.391 & 0.010 & 0.012 & 0.020 & 0.023 \\
\hline 19238 & 10840549 & 2010-11-17 09:46:15 (UTC) & 3.2 & 14.6 & 59.1 & 308 & 33.987 & -117.159 & 0.007 & 0.018 & 0.010 & 0.019 \\
\hline 6305 & 14442800 & 2009-04-09 21:45:31 (UTC) & 3.4 & 14.3 & 59.7 & 170 & 33.156 & -116.562 & 0.004 & 0.010 & 0.006 & 0.010 \\
\hline 18454 & 11034469 & 2011-11-19 20:32:21 (UTC) & 3.9 & 9.9 & 61.3 & 141 & 33.245 & -116.265 & 0.007 & 0.027 & 0.014 & 0.023 \\
\hline 6134 & 14429152 & 2009-03-13 03:42:22 (UTC) & 3.0 & 15.1 & 63.8 & 309 & 34.016 & -117.197 & 0.006 & 0.011 & 0.010 & 0.028 \\
\hline 19273 & 14889324 & 2010-12-01 19:31:34 (UTC) & 3.2 & 16.9 & 66.4 & 307 & 34.017 & -117.227 & 0.003 & 0.007 & 0.007 & 0.020 \\
\hline 19560 & 15293905 & 2013-03-04 23:17:41 (UTC) & 3.5 & 16.2 & 68.7 & 308 & 34.033 & -117.247 & 0.008 & 0.045 & 0.020 & 0.039 \\
\hline 19241 & 14883196 & 2010-11-17 23:58:43 (UTC) & 3.7 & 5.5 & 76.7 & 165 & 33.004 & -116.466 & 0.003 & 0.006 & 0.006 & 0.008 \\
\hline 5837 & 10370177 & 2009-01-09 04:47:40 (UTC) & 3.3 & 15.1 & 77.0 & 309 & 34.098 & -117.306 & 0.004 & 0.005 & 0.007 & 0.025 \\
\hline 5836 & 10370141 & 2009-01-09 03:49:46 (UTC) & 4.5 & 14.2 & 77.3 & 310 & 34.107 & -117.304 & 0.029 & 0.086 & 0.059 & 0.069 \\
\hline 6152 & 14433456 & 2009-03-24 11:55:44 (UTC) & 4.8 & 6.0 & 96.2 & 114 & 33.317 & -115.728 & 0.012 & 0.048 & 0.026 & 0.037 \\
\hline 18858 & 15189281 & 2012-08-08 16:33:22 (UTC) & 4.5 & 10.4 & 107.2 & 285 & 33.904 & -117.791 & 0.004 & 0.009 & 0.009 & 0.008 \\
\hline 18857 & 15189073 & 2012-08-08 06:23:34 (UTC) & 4.5 & 10.1 & 107.3 & 285 & 33.905 & -117.792 & 0.004 & 0.007 & 0.011 & 0.008 \\
\hline 18938 & 15223417 & 2012-10-02 08:28:15 (UTC) & 4.1 & 10.5 & 108.5 & 153 & 32.805 & -116.144 & 0.003 & 0.013 & 0.005 & 0.011 \\
\hline 19215 & 10832573 & 2010-11-04 19:40:00 (UTC) & 4.6 & 13.4 & 110.3 & 145 & 32.864 & -115.997 & 0.004 & 0.013 & 0.006 & 0.008 \\
\hline 18882 & 15199681 & 2012-08-26 19:31:23 (UTC) & 5.3 & 8.3 & 127.1 & 125 & 33.017 & -115.554 & 0.012 & 0.025 & 0.014 & 0.017 \\
\hline 18900 & 37088484 & 2012-08-26 19:31:23 (UTC) & 5.3 & 12.3 & 127.9 & 124 & 33.019 & -115.546 & 0.012 & 0.025 & 0.014 & 0.017 \\
\hline 4740 & 14745580 & 2010-06-15 04:26:58 (UTC) & 5.7 & 5.4 & 128.7 & 147 & 32.700 & -115.921 & 0.036 & 0.128 & 0.050 & 0.078 \\
\hline 4323 & 30253759 & 2010-04-05 11:14:15 (UTC) & 5.1 & 13.1 & 138.7 & 144 & 32.662 & -115.807 & 0.012 & 0.047 & 0.019 & 0.019 \\
\hline 4237 & 10597061 & 2010-04-10 09:12:28 (UTC) & 4.5 & 6.8 & 139.3 & 143 & 32.671 & -115.773 & 0.019 & 0.083 & 0.036 & 0.055 \\
\hline 4287 & 14609660 & 2010-04-05 03:15:25 (UTC) & 5.0 & 1.3 & 139.6 & 144 & 32.647 & -115.805 & 0.012 & 0.030 & 0.011 & 0.014 \\
\hline 4533 & 14718764 & 2010-05-22 17:33:18 (UTC) & 4.9 & 4.7 & 143.8 & 144 & 32.622 & -115.771 & 0.005 & 0.010 & 0.006 & 0.010 \\
\hline 4532 & 14718756 & 2010-05-22 17:30:58 (UTC) & 4.9 & 8.1 & 145.2 & 144 & 32.616 & -115.757 & 0.010 & 0.032 & 0.026 & 0.025 \\
\hline 4276 & 14607652 & 2010-04-04 22:40:42 (UTC) & 7.2( $\left(\mathrm{M}_{\mathrm{W}}\right)$ & 10.0 & 206.7 & 141 & 32.216 & -115.300 & 0.130 & 0.321 & 0.145 & 0.178 \\
\hline
\end{tabular}

Note: UID is the data file folder name from the NEES@UCSB database, EVENTID is the unique event identification number assigned in the Southern California Earthquake Data Center(SCEDC) catalog, $\mathrm{M}_{\mathrm{L}}$ and $\mathrm{M}_{\mathrm{W}}$ for the local magnitude and moment magnitude respectively, the distance is hypocentral distance determined by depth, latitude and longitude, the PGA and PRV are maximum absolute value after data processing. 